\title{
\begin{tabular}{l|l} 
Mitraries & DSpace@MIT
\end{tabular}
}

\author{
MIT Open Access Articles
}

\section{Measurements of Differential Reflectivity in Snowstorms and Warm Season Stratiform Systems}

The MIT Faculty has made this article openly available. Please share how this access benefits you. Your story matters.

Citation: Williams, Earle R., David J. Smalley, Michael F. Donovan, Robert G. Hallowell, Kenta T. Hood, Betty J. Bennett, Raquel Evaristo, et al. "Measurements of Differential Reflectivity in Snowstorms and Warm Season Stratiform Systems." Journal of Applied Meteorology and Climatology 54, no. 3 (March 2015): 573-595. (c) 2015 American Meteorological Society

As Published: http://dx.doi.org/10.1175/jamc-d-14-0020.1

Publisher: American Meteorological Society

Persistent URL: http://hdl.handle.net/1721.1/98390

Version: Final published version: final published article, as it appeared in a journal, conference proceedings, or other formally published context

Terms of Use: Article is made available in accordance with the publisher's policy and may be subject to US copyright law. Please refer to the publisher's site for terms of use. 


\title{
Measurements of Differential Reflectivity in Snowstorms and Warm Season Stratiform Systems
}

\author{
Earle R. Williams, David J. Smalley, Michael F. Donovan, Robert G. Hallowell, \\ KENTA T. HOOD, AND BETTY J. BENNETT
}

Lincoln Laboratory, Massachusetts Institute of Technology, Lexington, Massachusetts

\author{
Raquel Evaristo, Adam Stepanek, Teresa Bals-Elsholz, Jacob CobB, and Jaclyn Ritzman \\ Valparaiso University, Valparaiso, Indiana
}

AleXeI KOROLEV

Environment Canada, Toronto, Ontario, Canada

Mengistu Wolde

National Research Council of Canada, Ottawa, Ontario, Canada

(Manuscript received 31 December 2013, in final form 19 September 2014)

\begin{abstract}
The organized behavior of differential radar reflectivity (ZDR) is documented in the cold regions of a wide variety of stratiform precipitation types occurring in both winter and summer. The radar targets and attendant cloud microphysical conditions are interpreted within the context of measurements of ice crystal types in laboratory diffusion chambers in which humidity and temperature are both stringently controlled. The overriding operational interest here is in the identification of regions prone to icing hazards with long horizontal paths. Two predominant regimes are identified: category A, which is typified by moderate reflectivity (from 10 to $30 \mathrm{dBZ}$ ) and modest + ZDR values (from 0 to $+3 \mathrm{~dB}$ ) in which both supercooled water and dendritic ice crystals (and oriented aggregates of ice crystals) are present at a mean temperature of $-13^{\circ} \mathrm{C}$, and category $\mathrm{B}$, which is typified by small reflectivity (from -10 to $+10 \mathrm{dBZ}$ ) and the largest + ZDR values (from +3 to $+7 \mathrm{~dB}$ ), in which supercooled water is dilute or absent and both flat-plate and dendritic crystals are likely. The predominant positive values for ZDR in many case studies suggest that the role of an electric field on ice particle orientation is small in comparison with gravity. The absence of robust $+\mathrm{ZDR}$ signatures in the trailing stratiform regions of vigorous summer squall lines may be due both to the infusion of noncrystalline ice particles (i.e., graupel and rimed aggregates) from the leading deep convection and to the effects of the stronger electric fields expected in these situations. These polarimetric measurements and their interpretations underscore the need for the accurate calibration of ZDR.
\end{abstract}

\section{Introduction}

This study is concerned with systematic positive signatures in radar differential reflectivity (ZDR) in the cold regions of stratiform precipitation, and with their implications for aircraft icing hazard. It is now widely recognized that ice crystals and aggregates of ice crystals are anisotropic targets for dual-polarization radar. This

Corresponding author address: Earle Williams, MIT Lincoln Laboratory, 244 Wood St., Lexington, MA 02420.

E-mail: earlew@1l.mit.edu organized behavior of ice particles in stratiform conditions is not a new observation, and has been previously documented both in winter storms (Sauvageot et al. 1986; Moisseev et al. 2009; Kennedy and Rutledge 2011; Thompson et al. 2014) and in the warm season (Herzegh and Conway 1986; Hall et al. 1984; Bader et al. 1987; Andric et al. 2013). The main purpose here is to document two kinds of radar signature (hereinafter referred to as categories A and B) in as wide a variety of meteorological scenarios as possible. The interest here is an operational one. NEXRAD instruments are now configured for dual-polarization capability. We seek to make 
use of this new capability to identify regions that may be characterized by supercooled water and, thereby, present an icing hazard to aviation. The incentive here is not a new one (Hudak et al. 2002; Plummer et al. 2010). Within this context, the established connection between ice particle shape on the one hand, and humidity and temperature on the other (Bailey and Hallett 2009), is of paramount importance. The differential reflectivity is influenced by both particle shape and orientation. The orientation of ice crystals is influenced by both gravity and the local electrostatic field (Weinheimer and Few 1987), and stratiform precipitation is known to be electrified in both summer and winter. While many radar polarimetric observations have been made on active thunderstorms (Metcalf 1993, 1995, 1997; Krehbiel et al. 1996), less attention has been paid to stratiform situations that are marginal lightning producers.

The broad outline for the organization of this paper consists of a section on background aspects germane to interpreting the observations, followed by the observations themselves. The background section includes a summary of ZDR response on a range of hydrometeor shapes (section 2a), a review of laboratory diffusion chamber measurements with empirical control of crystal shape by humidity and temperature (section $2 \mathrm{~b}$ ), and a discussion of the role of updraft speed and ice crystal population in controlling the in situ humidity condition (section $2 \mathrm{c}$ ), followed by preliminary aircraft microphysical measurements aimed at verification of ice particle types detected by one NEXRAD site (section $2 \mathrm{~d}$ ). The observations consist of a description of two categories of ZDR return, followed by a number of miniature case studies, first with a collection of winter storm cases documented with a C-band polarimetric radar in Valparaiso, Indiana, and second by a set of warm season cases made possible by multiple NEXRAD sites. The presentation of observations is followed by some discussion and our conclusions.

One anonymous reviewer of this paper favored rejection of the manuscript because the conclusions were not validated by aircraft measurements. Now in print, this work is one addition to a large collection of published studies on polarimetric radar measurements (Jameson et al. 1996; Caylor and Chandrasekhar 1996; Krehbiel et al. 1996, Metcalf 1993; Kennedy and Rutledge 2011; Andric et al. 2013; Bechini et al. 2013) with microphysical interpretations but without in situ validations.

\section{Interpretational background}

\section{a. Anisotropy of hydrometeors: Theoretical considerations}

Historically, differential reflectivity methods were advanced with the promise of better characterization of raindrops and improved measurements of rainfall (Seliga and Bringi 1976). The anisotropy of gravityoriented hydrometeors is controlled primarily by their aspect ratio (sometimes called the axis ratio or the ratio of the horizontal to vertical axes). For the largest raindrops this aspect ratio can reach $\sim 2$ (Bringi and Chandrasekar 2001), with associated ZDR values from +5 to $+7 \mathrm{~dB}$ (Teschl et al. 2008). Departures from perfectly stable horizontal orientation will dilute the differential reflectivity of anisotropic crystals (Matrosov et al. 2005) in a process called flutter. Given existing measurements of the standard deviation of crystal orientation from the horizontal $\left[1^{\circ}-2^{\circ}\right.$, Noel and Sassen (2005); $9^{\circ}$, Matrosov et al. (2005)], these departures are expected to be modest (Dissanayake et al. 1983).

Most ice crystals are substantially smaller than large raindrops and, along with ice scattering less than liquid, when in the Rayleigh regime, exhibit dramatically smaller reflectivity in general. However, the aspect ratios and corresponding ZDR values for ice crystals can greatly exceed those of raindrops. The most anisotropic crystals to radar are the flat (solid) hexagonal plates, and measurement of such crystals in natural clouds show aspect ratios of 20-50 (Auer and Veal 1970). According to theoretical calculations by Dissanayake et al. (1983), Hogan et al. (2002), and Steinert and Chandra (2009), the ZDR values for such gravity-oriented crystals can reach $+9 \mathrm{~dB}$. Earlier radar-aircraft comparisons had associated anisotropic crystals with the existence of supercooled water (Field et al. 2004).

Raindrops and solid hexagonal plates are convex shapes whose radar cross sections are well approximated by oblate spheroids with variable aspect ratios. Many other dominant snowstorm hydrometeors have distinctly concave shapes-most notably dendritic crystals and aggregates of crystals otherwise known as snowflakes. Calculations by Vivekanandan et al. (1994) illustrated in Fig. 1 have shown that concavity of shape can strongly dilute the anisotropy and ZDR values. When concave shapes are characterized by their mean volume fraction of ice, the ZDR value of a plate crystal with full volume fraction (1.0) and +9 ZDR has its ZDR diluted to $+5 \mathrm{~dB}$ for volume fraction 0.5 and to $+1 \mathrm{~dB}$ for a volume fraction of 0.1 .

Within this context, Wolde and Vali (2001a), in W-band radar polarimetric measurements from aircraft, have recorded $\mathrm{ZDR}$ values from +6 to $+7 \mathrm{~dB}$ on a mixture of plates and sector plates, and from +1 to $+2 \mathrm{~dB}$ values on dendritic crystals. Verified by in situ particle imaging methods, these results provide considerable motivation to use differential reflectivity measurements to characterize snowstorm hydrometeors toward constraining the 


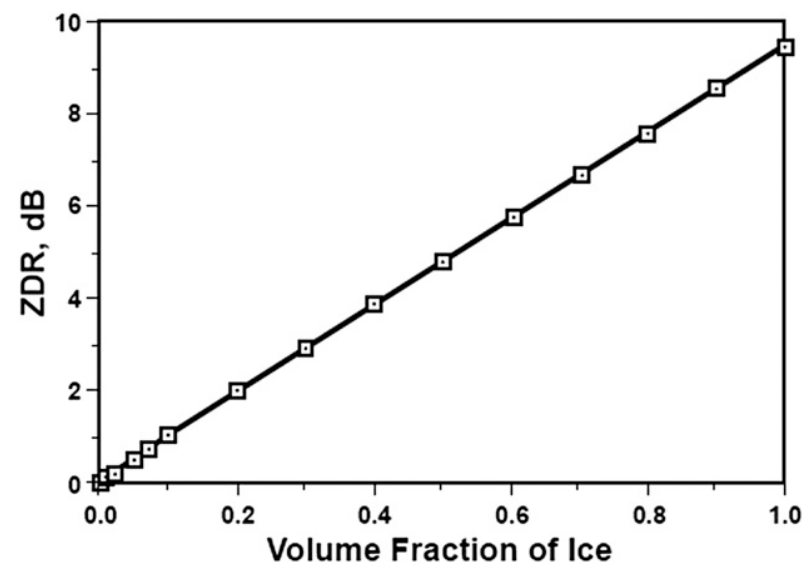

FIG. 1. Dilution of ZDR of ice crystals by convex shapes [based on Vivekanandan et al. (1994)], Solid plate ice crystals (volume fraction of ice $=1$ ) yield significantly higher ZDR values than do dendrite ice crystals ( $\sim 0.5$ volume fraction of ice).

microphysical situation. The flat-plate crystals observed by Wolde and Vali (2001a) were not noticeably rimed, but it is worth noting that the riming of ice crystals can only serve to dilute their anisotropy (by primary thickening of the crystal and reduction of the aspect ratio and increasing concavity) and lessen their positive differential reflectivity values (hereinafter designated $+\mathrm{ZDR}$ values).

\section{b. Temperature and humidity control on ice crystal habits}

The empirical dependence of ice crystal habit on temperature and humidity is well established on the basis of laboratory measurements with diffusion chambers (Hallett and Mason 1958; Mason et al. 1963; Bailey and Hallett 2009), and by observations in natural conditions during winter (Magono and Lee 1966). Broad consistency is apparent between the two sets of measurements, but greater reliance on the laboratory observations is usually recommended owing to the accurate control on humidity with respect to liquid water in the diffusion chamber.

Figure 2 shows the latter results from Bailey and Hallett (2009). Routine meteorological observations of humidity do not enable a clear distinction between the conditions of ice saturation and water saturation, a distinction of considerable importance to the crystal habit diagram and to the present study. Figure 2 shows the important water saturation boundary (arcing, red curve), across which a change in crystal habit is evident for every range of temperature in conditions of ice supersaturation. (A condition of ice supersaturation is present at water saturation, and so the former condition is prevalent over the entirety of Fig. 2.) This diagram is consistent with

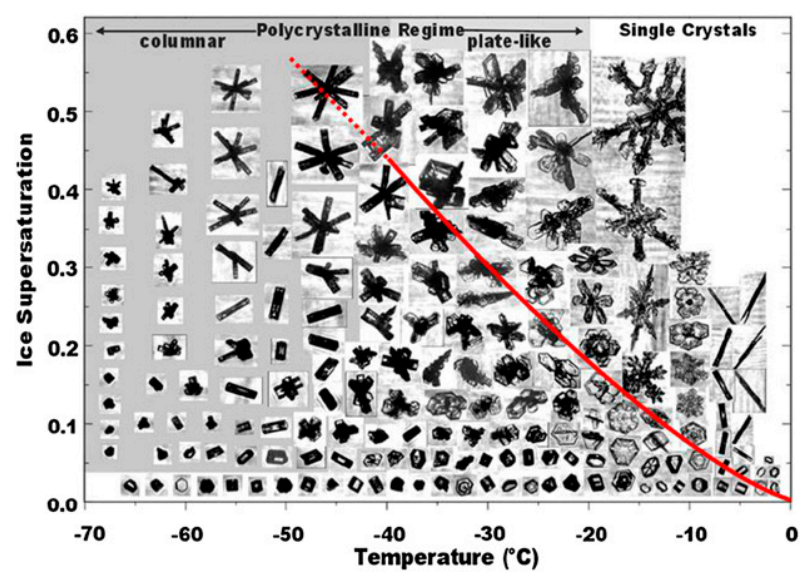

FIG. 2. Detailed crystal habit diagram, with temperature and humidity dependence, from Bailey and Hallett (2009). The red line represents water saturation with subsaturation to the left and supersaturation to the right.

their more detailed diffusion chamber results. Stronger gradients in water vapor concentration expected above the red sloping water saturation line are generally associated (empirically) with larger ice crystal anisotropy. Based on the considerations of hydrometeor anisotropy in the previous section, one can also expect a substantial diminishment in + ZDR values from the ice-supersaturated region to the water-saturated region.

\section{c. Humidity control by the lifting process}

In a laboratory environment, ice saturation conditions can be achieved by a static isothermal environment with ice and vapor in equilibrium. Water saturation conditions can also be achieved by an environment with ice, vapor, and supercooled droplets in coexistence. In the real atmosphere, supersaturation (ice or water) is controlled by ascent and adiabatic expansion, competing with vapor condensation and deposition on particles. Korolev and colleagues have given experimental and theoretical attention to the mixed-phase conditions in winter storms in a series of papers (Korolev et al. 2000; Korolev and Isaac 2006; Korolev 2007; Korolev and Field 2008). Korolev and Mazin (2003) have made theoretical calculations of the full range of possible supersaturation conditions, as shown in their Fig. 5, which has been adapted for this study here as illustrated in Fig. 3. Three horizontal lines represent the condition of water saturation for three particular temperatures $\left(-5^{\circ},-15^{\circ}\right.$, and $\left.-35^{\circ} \mathrm{C}\right)$. The sloping lines represent the steady-state supersaturation for three different updraft speeds $\left(10 \mathrm{~m} \mathrm{~s}^{-1}, 1 \mathrm{~m} \mathrm{~s}^{-1}\right.$, and $\left.10 \mathrm{~cm} \mathrm{~s}^{-1}\right)$. The number concentration of ice crystals is $N\left(\mathrm{~cm}^{-3}\right)$ and $r$ is the mean crystal radius $(\mu \mathrm{m})$. Smaller updraft speeds are sufficient for a water saturation condition if the crystal population 


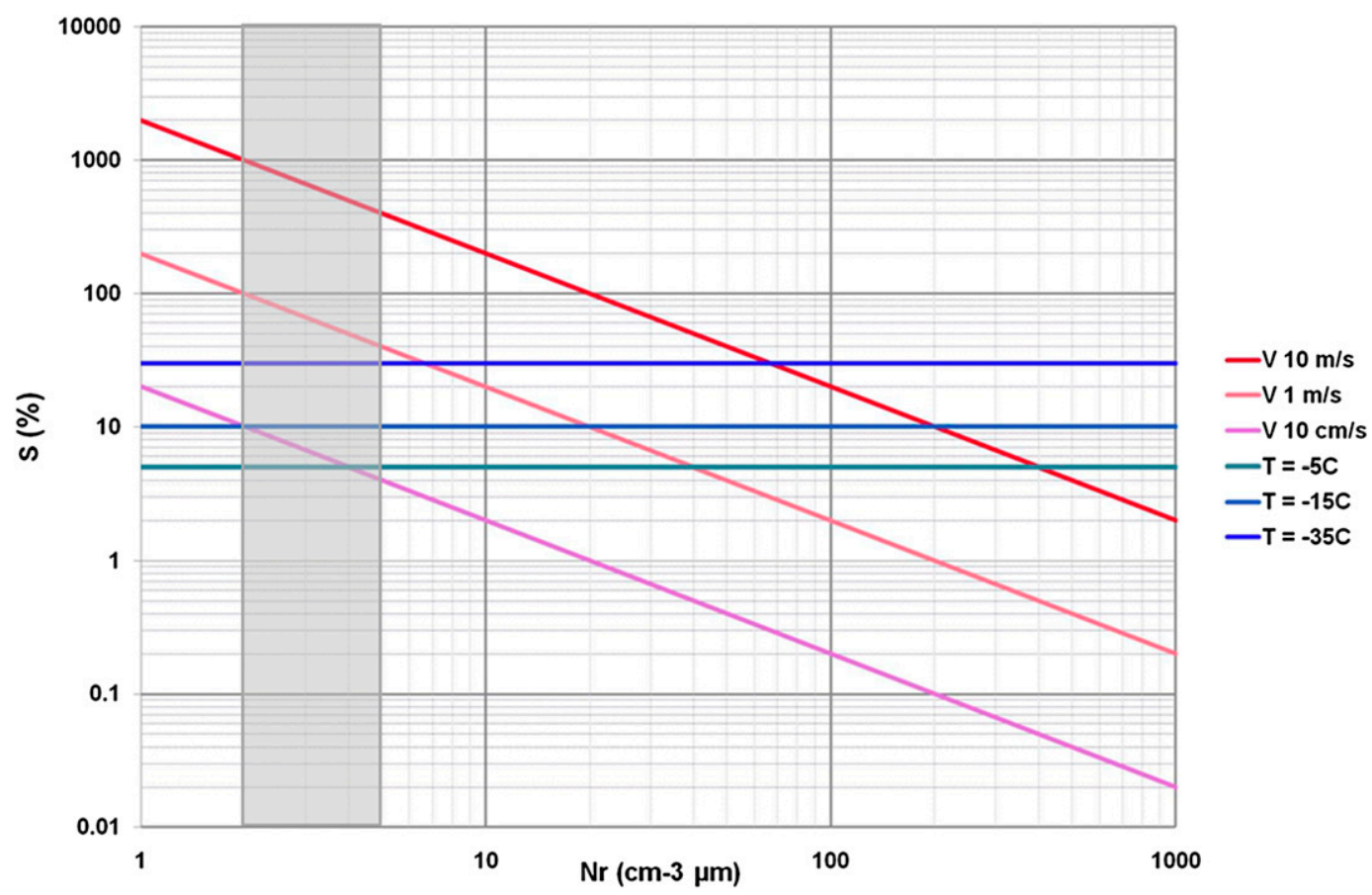

FIG. 3. Predicted updraft requirements for supercooled water as a function of the product of the concentration of ice particles $N$ and their mean radius $r$. The vertical axis measures the supersaturation $S$ with respect to ice. The grayshaded region represents the range of values of the $N r$ parameter measured by aircraft in regions where radar measurements suggest category A behavior. [Adapted from Korolev and Mazin (2003).]

quantity $\mathrm{Nr}$ is dilute, because the sink for water vapor in steady state is reduced. For example, for an $\mathrm{Nr}$ value of $5 \mathrm{~cm}^{-3} \mu \mathrm{m}$ in the center of the gray-shaded zone, and for an in situ temperature of $-5^{\circ} \mathrm{C}$, a water-saturated condition with supercooled water is expected for an updraft speed of $\sim 10 \mathrm{~cm} \mathrm{~s}^{-1}$. If ice nuclei are abundant, $N r$ will be large, and supercooled water suppressed. But if the updraft speed is sufficiently large, water-supersaturated conditions and the presence of supercooled water (and hence icing conditions) will prevail. A range of updraft speed is also predicted for ice supersaturation without supercooled water in which pristine ice crystals can continue to grow by vapor deposition without riming. For temperatures common to dendritic crystal growth (recall Fig. 2), the Korolev and Mazin work suggests a vertical velocity slightly in excess of $10 \mathrm{~cm} \mathrm{~s}^{-1}$ would be necessary.

Occasionally in winter one sees evidence for the glory rings in cold-topped stratocumulus clouds over distances of hundreds to thousands of kilometers in flights with commercial aircraft. The suggestion from Fig. 3 is that the ice crystal populations $\mathrm{Nr}$ are sufficiently small that very modest ascent is able to maintain supercooled water droplets (and an icing hazard), essential for the diffraction phenomenon of the glory. The radar response to such glory conditions is expected to be challenging for the identification of a potential icing hazard, because the cloud droplets are necessarily small (no larger than 28- $\mu \mathrm{m}$ diameter).

\section{d. Aircraft measurements of cloud microphysics as verification of NEXRAD polarimetric radar observations}

On 24 February 2012, MIT Lincoln Laboratory collaborated with the National Research Council of Canada with their Convair 580 aircraft to make in situ microphysical measurements of snowstorms. The main target of investigation was a storm over Lake Erie under surveillance by the NEXRAD in Cleveland, Ohio (KCLE), recently configured with polarimetric capability. A pronounced + ZDR signature, with maximum values of $+5 \mathrm{~dB}$, was observed in a region characterized by modest reflectivity $(\sim 20 \mathrm{~dB} Z)$, an in situ temperature of $-15^{\circ} \mathrm{C}$, a humidity condition close to water saturation, and an abundance of dendritic ice crystals with maximum diameters up to $1.5 \mathrm{~mm}$. Sample images from the 2DC probe (with 50- $\mu \mathrm{m}$ pixel resolution) are shown in Fig. 4, where the width of the image strip is $1.6 \mathrm{~mm}$. The crystals appear to be pristine, with no obvious evidence of riming, consistent with the small supercooled water content 


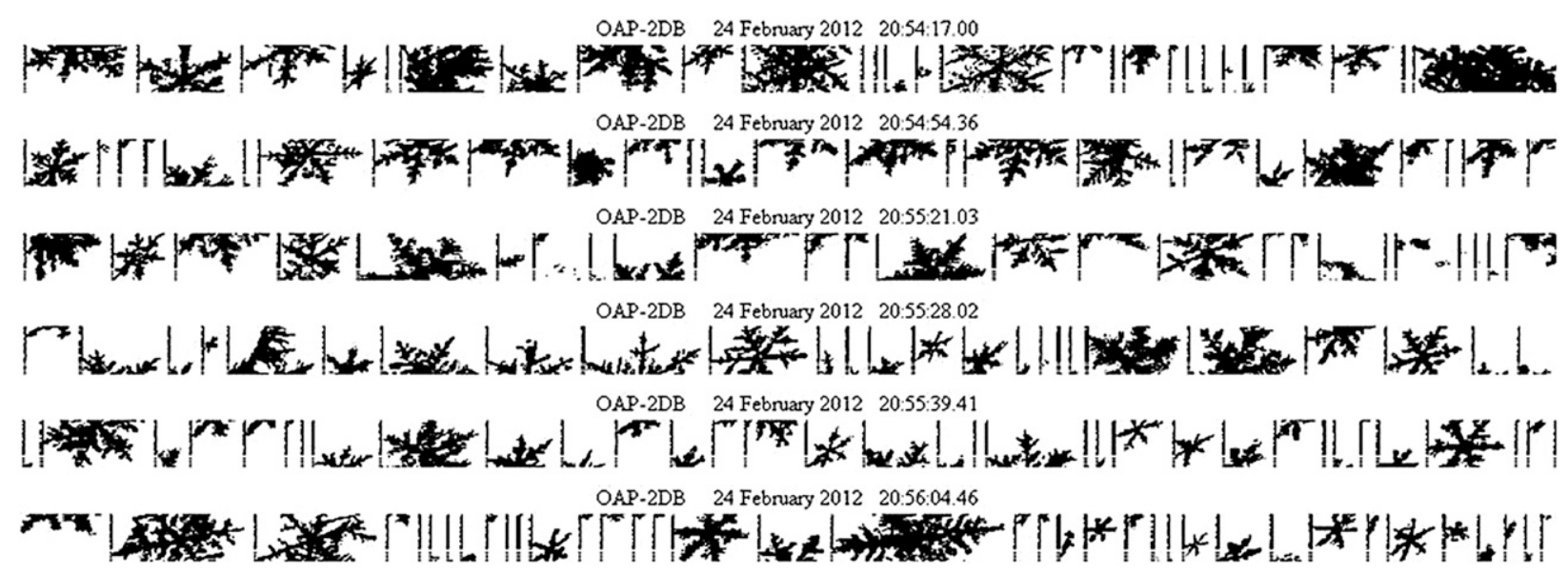

FIG. 4. Sample images from the 2DC particle imager on the Convair 580 research aircraft during a time (2054-2056 UTC) when the KCLE polarimetric radar was detecting +5 - $\mathrm{dB}$ differential reflectivity in the vicinity of the aircraft in a radar return characterized in this study as category B. The image width (distance between vertical lines) is $1.6 \mathrm{~mm}$. The pixel resolution is $50 \mu \mathrm{m}$. Large flat dendritic crystals are evident.

$\left(<0.1 \mathrm{~g} \mathrm{~m}^{-3}\right)$ detected at this time. This observation with the 2DC probe lacks the resolution necessary to rule out the possibility of light riming. [The existence of supercooled water is consistent with the expectation of the diffusion chamber measurements (Fig. 2) that watersaturated conditions are needed for dendrites.] The $+5-\mathrm{dB}$ value for $\mathrm{ZDR}$ is consistent with the predictions in Fig. 1, given the volume fraction evident in Fig. 4. This in situ icing mission is considered an encounter with a category B microphysics regime (see section $3 b$ ), because of both the large ZDR value and the shape of the region. In a later interval during the same flight, a region of supercooled water $\left(0.03 \mathrm{~g} \mathrm{~m}^{-3}\right)$ at a temperature of $-18^{\circ} \mathrm{C}$ was encountered. The in situ reflectivity was larger $(30-40 \mathrm{dBZ})$ and the differential reflectivity smaller $(+1 \mathrm{~dB})$, all evidence consistent with the presence of riming with an attendant dilution of ZDR. Clearly, the potential for polarimetric NEXRAD to detect certain microphysical conditions is demonstrated by in situ verification.

\section{Radar polarimetric observations at $\mathrm{C}$ and $\mathrm{S}$ bands}

Radar polarimetric observations of midwestern storms have been carried out with the C-band polarimetric radar (Enterprise Electronics Corporation) in Valparaiso. The operating characteristics of this radar are $P_{t}=$ $250 \mathrm{~kW}$, antenna diameter is $4.3 \mathrm{~m}$, antenna gain is $45 \mathrm{~dB}$, beamwidth is $0.91^{\circ}$, pulse length is $0.8 \mu \mathrm{s}$, and wavelength is $5.3 \mathrm{~cm}$. The exceptionally large antenna size at $\mathrm{C}$ band endows this radar with considerable sensitivity for weak targets. A large number of snowstorms have been documented with full volume scans and occasional range-height indicator (RHI) scans during the 2009-11 winter seasons. The volume scans followed the design of NEXRAD's volume coverage pattern (VCP) 11: 14 elevation angles between $0.5^{\circ}$ and $19.5^{\circ}$ during a 5-min period. The two principal storm types have been synoptic/ warm-frontal progressions from the south and west and the "lake effect" storms due to northerly transport of moisture off Lake Michigan, whose long north-south axis is roughly aligned with the longitude of Valparaiso. The radar observations in Valparaiso have been supplemented with local thermodynamic soundings (when wind conditions allow) carried out by teams of meteorology students, whose principal purpose is to document the in situ temperatures at which pronounced anomalies in polarimetric parameters are observed (see Fig. 16).

NEXRAD S-band polarimetric observations from St. Louis, Missouri; Morehead City, North Carolina; Seattle, Washington; and Norman, Oklahoma, were also analyzed for a variety of storm types. The nominal operating characteristics of these radars are $P_{t}=1000 \mathrm{~kW}$, beamwidth $=0.95^{\circ}$, pulse widths $=1.5$ or $4.5 \mu \mathrm{s}$, and wavelength $=10 \mathrm{~cm}$. The examined cases include inland remnants of a hurricane, a Pacific coast occluded front, an Atlantic hurricane, and squall lines. Local thermodynamic soundings are not available specifically for the analysis of these cases as they were in Valparaiso.

\section{a. Calibration of differential reflectivity at $C$ band}

Interpretation of ZDR and the physical distinctions we have sought to make among snowstorm hydrometeors [as discussed in section 2a for plate crystals, dendrite crystals, and aggregates of crystals ("snowflakes")] as summarized in Table 1 require an accuracy in ZDR 
TABLE 1. Categorization of microphysical regimes.

\begin{tabular}{|c|c|c|}
\hline Category A & Category B & Uncategorized \\
\hline Water-saturated conditions & Ice-supersaturated conditions & Ice- or water-saturated conditions \\
\hline Dendrite crystals & High aspect ratio crystals & Aggregates of crystals \\
\hline+ ZDR brightband layers & Patches and edges & Not evident as a distinct feature \\
\hline Rings in PPI displays & No rings in PPI displays & 3D relationships involved \\
\hline Stronger updraft & Weaker updraft & Strong updraft (if riming) \\
\hline Larger reflectivity (10-30 dBZ) & Small reflectivity (from -10 to $+10 \mathrm{~dB} Z$ ) & Largest reflectivity $(20-30 \mathrm{dBZ})$ \\
\hline $\begin{array}{l}\text { Weak }+\mathrm{ZDR} \text { (from }+1 \text { to }+3 \mathrm{~dB} \text { ) but } \\
\text { stronger than surrounding layers }\end{array}$ & Large $+\mathrm{ZDR}($ from +4 to $+8 \mathrm{~dB})$ & Weakest + ZDR (from 0 to $+2 \mathrm{~dB}$ ) \\
\hline Icing hazard & No icing hazard & Possible icing hazard \\
\hline $\begin{array}{l}\text { Potential viable source of } \\
\text { supercooled water }\end{array}$ & Supercooled water unlikely & $\begin{array}{l}\text { Complex situation that might include } \\
\text { viable supercooled water }\end{array}$ \\
\hline In situ measurements needed & In situ verified & More in situ measurements needed \\
\hline
\end{tabular}

measurements of a fraction of a decibel (dB). While the stringent $0.1-\mathrm{dB}$ accuracy specification for the new NEXRAD polarimetric capability in ZDR has not been attained for this study, an accuracy in the range of $0.3-$ $0.4 \mathrm{~dB}$ has been achieved by making observations with the C-band radar at vertical incidence, when circular cross sections are presented as radar targets. These calibration checks are performed whenever opportunities arise. Figure 5 shows an example of the uniformity of ZDR (right panel) in a vertical profile in stratiform rain from 1- to 5-km altitude. The offset of ZDR from $0 \mathrm{~dB}$ ranges from 0 to $0.3 \mathrm{~dB}$.

For NEXRAD S-band instruments, calibration checks at vertical incidence are not possible for hardware reasons. Instead, alternative techniques (e.g., Cunningham et al. 2013) are under evaluation by the NEXRAD Radar Operations Center engineering team to implement suitable calibration checks. In the meantime, with the network fully polarimetric, anecdotal approaches are being performed to gain a sense of the radars' calibration and the stability of that calibration. A primary approach involves the analysis of $Z$ and ZDR returns in believed-to-be light-rain conditions beneath the melting layer as compared with calculated values from a large amount of disdrometer drop size distributions. Another approach involves expectations of ZDR in regions classified as dry snow by the NEXRAD hydrometeor classification algorithm. Yet another method is based on Bragg scatter in clear-air conditions (V. Melnikov 2013, personal communication). These nonvertical incidence scanning approaches have limitations in defining the calibration state of a radar. Further, results have been mixed. A general sense based on radar intercomparisons with the network is that a polarimetric radar tends to drift negatively in ZDR when calibration issues arise. For cases reported here, the NEXRADs appear to be functioning satisfactorily.

\section{b. Case studies}

The ZDR observations of winter storms in northern Indiana with the Valparaiso C-band dual-polarization radar tend to fall in two groups, our categories A and B. Similar winter storm observations are observed in the NEXRAD dual-polarization data. We later found these categories to also be useful in describing warm season stratiform systems that are also part of this study. The general characteristics of these two groups are summarized in Table 1 . The selection of a dominant hydrometeor type in category A (dendrite crystals) and category B (high aspect ratio crystals) is based primarily on the in situ microphysical verifications of Wolde and Vali (2001a), with simultaneous polarimetric radar observations. Additional considerations are based on the theoretical ZDR calculations of Vivekanandan et al. (Fig. 1) and Hogan et al. (2002). A key aspect of these categories is their radar presence as viewed in plan position indicator (PPI) format. Typically, category A is seen within the context of a full PPI scan with category B associated with the edges of detectable echo or as a "cap" over the top of the radar returns. A third column (without categorization) acknowledges the importance of the presence of crystal aggregation to form snowflakes. The radar returns in this case are more muted and less unique from a polarimetric PPI perspective. However, their gravity-induced presence is beneath that of the pristine crystals, particularly dendrites, suggesting that three-dimensional analysis is more appropriate for identification of this category.

Following this general identification scheme, selected case studies from each of these two categories have been chosen for presentation and discussion. A common fourpanel display format is used for all cases, including (a) a PPI display of radar reflectivity $Z$ (top left), (b) a PPI of differential reflectivity ZDR (top right), (c) the inferred atmospheric temperature on the PPI surface based on 
REFLECTIVITY (dBZ)

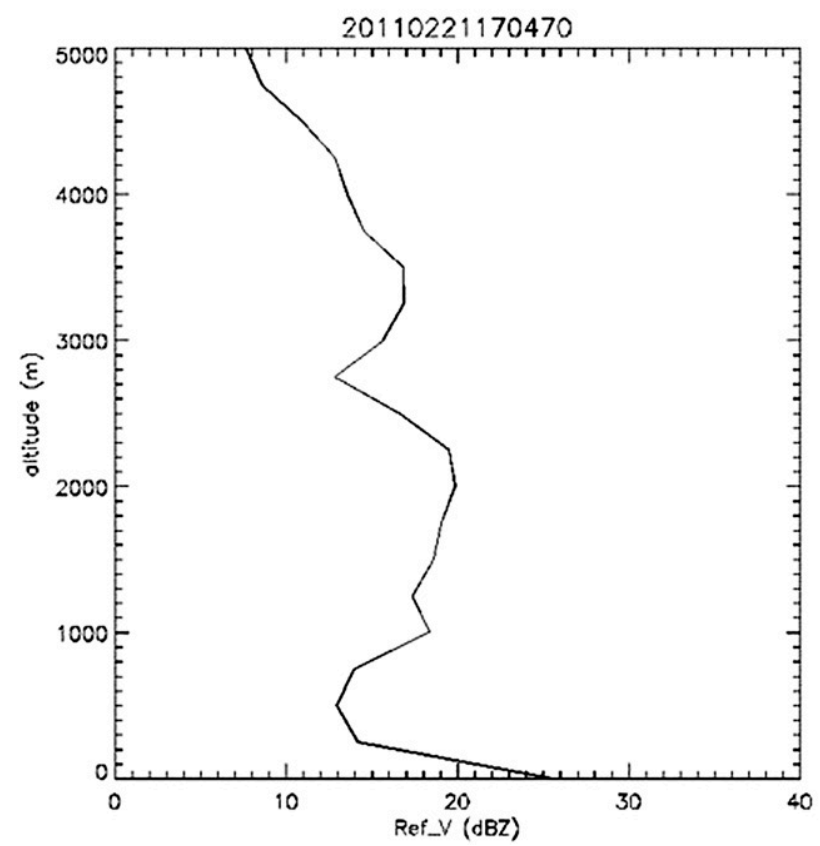

ZDR (dB)

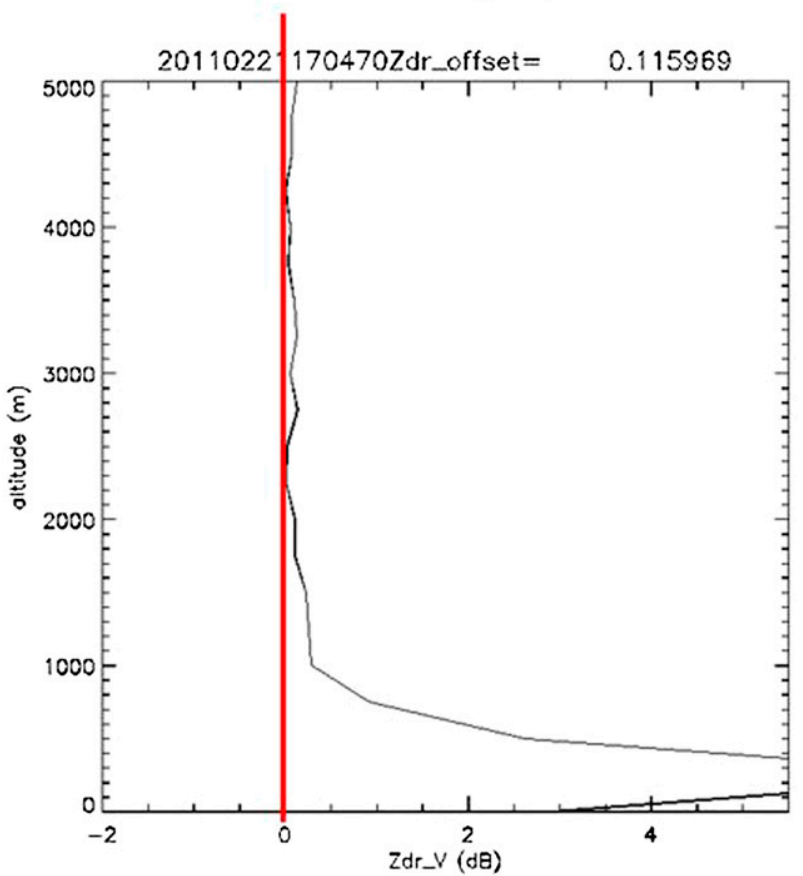

FIG. 5. Sample ZDR calibration run in vertically pointing mode on stratiform precipitation with the Valparaiso University C-band polarimetric radar: (left) reflectivity and (right) ZDR.

a proximity thermodynamic sounding or a Weather Research and Forecasting Model Rapid Refresh (RAP) $13-\mathrm{km}$ model profile when the proximity sounding was not available (bottom left), and (d) a scatterplot (bottom right) of $Z$ versus ZDR from individual range bins within a selected range-azimuth-limited sector with a red boundary as illustrated in panels a-c. One reviewer was concerned about the use of this model temperature field in place of actual proximity soundings, but several comparisons between model and sounding data when both were available showed agreement at the $1^{\circ} \mathrm{C}$ level. For the selected cases, a representative PPI is presented that best highlights the feature of interest. Often the feature is most prominent in one PPI but is also evident in adjacent PPIs of a full radar volume scan but with less magnitude as a result of the relationship of the available radar scanning angles to the ambient structure of the atmosphere being sensed.

\section{c. Winter storm case studies}

\section{1) 2357 UTC 8 DECEMBER 2009, $14.0^{\circ}$ PPI: CATEgOry A}

Category A behavior is well illustrated by the case in Fig. 6. The storm at this time features a double melting layer as evident in the sonde temperature plot (Fig. 6c) and Fig. 6e, and the two melting-layer transitions occur at about $1.95-\mathrm{km}$ altitude (radar range $8 \mathrm{~km}$ ) and very near the surface. Also evident to the west of the radar at 20-km range in the ZDR plot (Fig. 6b) is the +ZDR "brightband" anomaly. The category A feature is located about $4.8 \mathrm{~km}$ above ground level (AGL) where temperatures are around $-15^{\circ} \mathrm{C}$. ZDR values peak at a bit over $+3.5 \mathrm{~dB}$ in an area of reflectivity around $20 \mathrm{dBZ}$. The conditions at this temperature are represented in the crystal habit diagram as dendrites in a water-saturated environment. A sense of the depth of this layer of inferred icing hazard layer can be estimated. For this feature, the depth is $\sim 1 \mathrm{~km}$ with a $3^{\circ}-4^{\circ} \mathrm{C}$ temperature spread. Tracking this feature with time can give an indication of the atmosphere's ability to sustain an icing hazard.

\section{2) 1859 UTC 24 FEBRUARY 2010, $4.3^{\circ}$ PPI: CATEGORY A}

This warm-frontal snowstorm with atmospheric temperature everywhere $<0^{\circ} \mathrm{C}$ and illustrated in Fig. 7 shows evidence for a distinct positive ZDR anomaly $(+2 \mathrm{~dB})$ in a ring segment of the PPI to the east of the radar. The in situ temperature there is $-13^{\circ} \mathrm{C}$, compatible with the idea that dendritic crystals, growing near water saturation in ascending air over a large area, are the dominant $Z D R$ targets. The maximum reflectivity in this +ZDR bright band is $20-25 \mathrm{dBZ}$, consistent with 

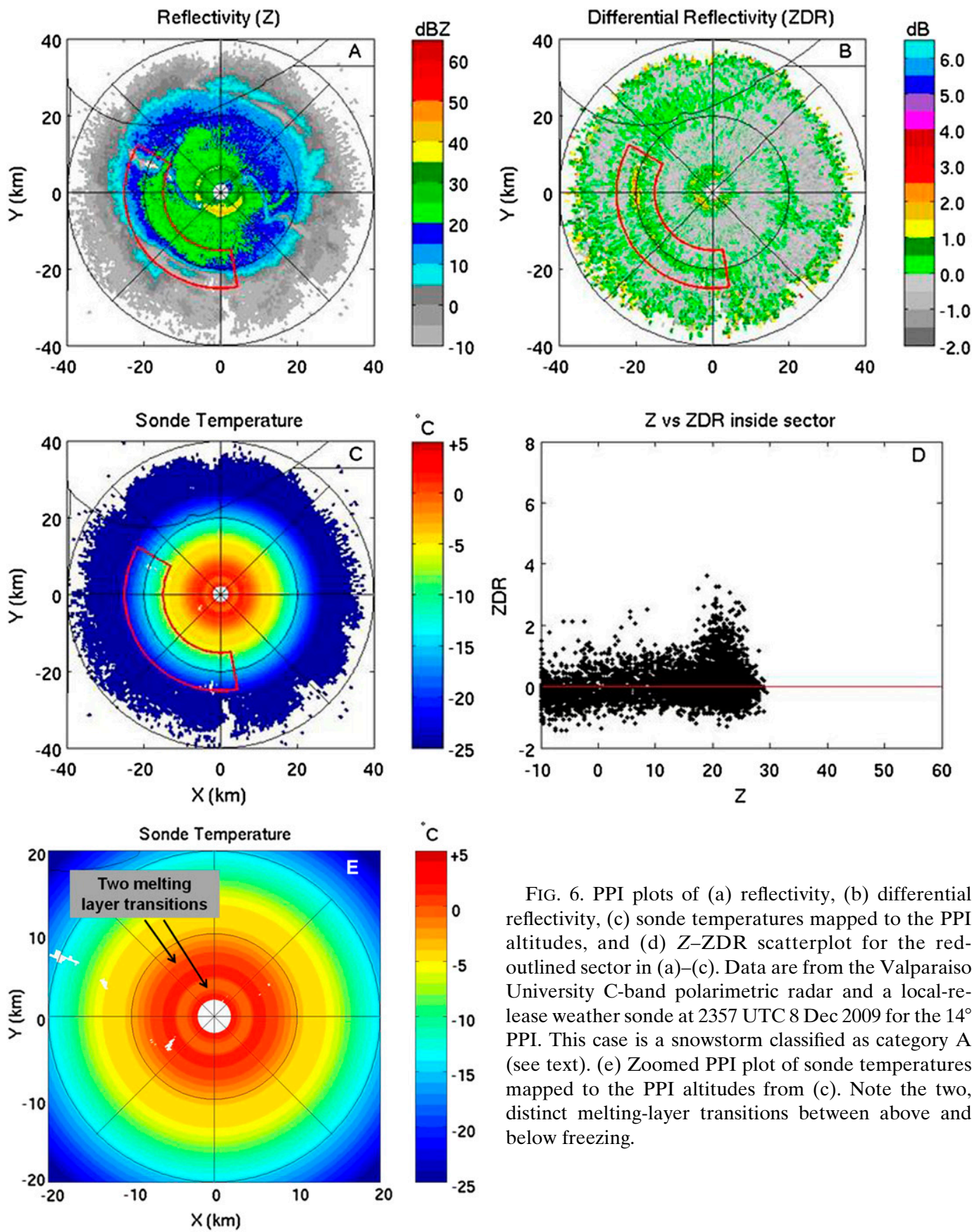

FIG. 6. PPI plots of (a) reflectivity, (b) differential reflectivity, (c) sonde temperatures mapped to the PPI altitudes, and (d) Z-ZDR scatterplot for the redoutlined sector in (a)-(c). Data are from the Valparaiso University C-band polarimetric radar and a local-release weather sonde at 2357 UTC 8 Dec 2009 for the $14^{\circ}$ PPI. This case is a snowstorm classified as category A (see text). (e) Zoomed PPI plot of sonde temperatures mapped to the PPI altitudes from (c). Note the two, distinct melting-layer transitions between above and below freezing.

the general characteristics for a category A feature. This case also illustrates the common absence of a ring over the full $360^{\circ}$ of azimuth, and some evidence for "spiraling" of the anomalous feature is apparent, suggesting that temperature is not a unique function of altitude everywhere within radar surveillance. Also visible in the western margins of the reflectivity and ZDR fields is evidence for category $\mathrm{B}$ behavior: some of the largest $+\mathrm{ZDR}$ values $(+4 \mathrm{~dB})$ are found in weak reflectivity $(<0 \mathrm{~dB} Z)$.

\section{3) 1625 UTC 8 JANUARY $2010,4.3^{\circ}$ PPI CATEGORY B}

Figure 8 illustrates features of a lake-effect storm south of Lake Michigan (see the lake boundary in this figure) that is relatively compact (with a PPI width of only $\sim 30 \mathrm{~km}$ ) in comparison with the warm-frontal storms at the synoptic scale (24 February 2010, previously described; 1 February 2011, described below) 

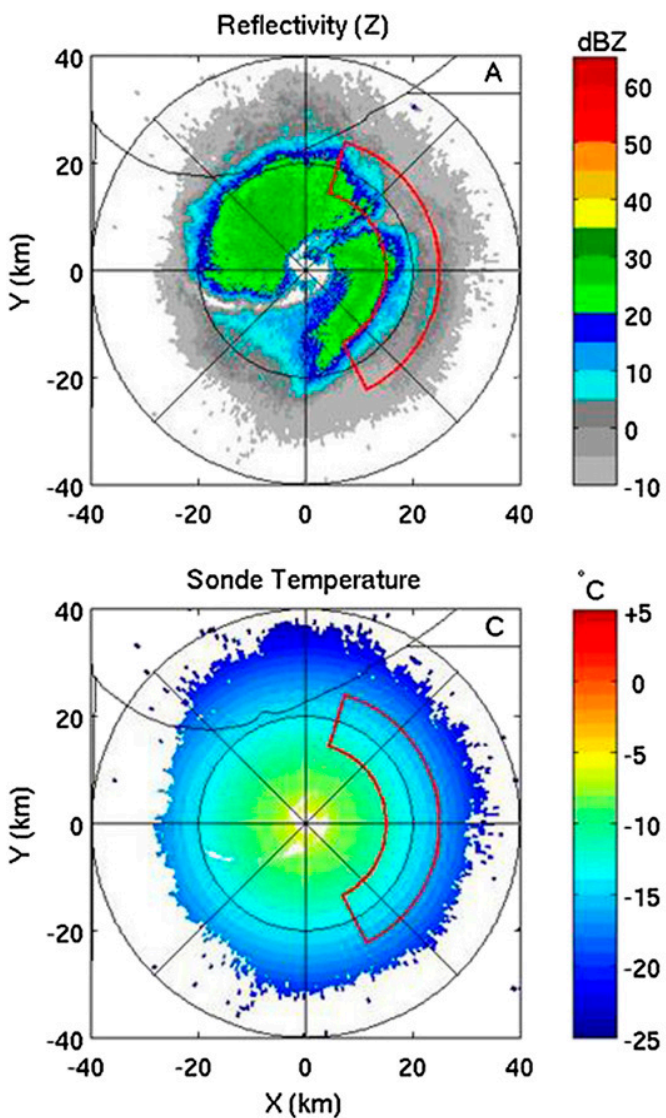

FIG. 7. As in Fig. 6, but for 1859

also included as case studies in the winter storms category. The ZDR anomaly for this storm manifests itself as a distinct edge effect, or cap, around the entire upper periphery of the storm, with maximum values reaching from +5 to $+6 \mathrm{~dB}$. (These measurements in weak reflectivity have been verified to have signal-to-noise ratios $>5 \mathrm{~dB}$.) This storm is so compact and centered on the radar that the radar beam is intersecting the reflectivity "edge" at all azimuths. This case lacks the circular symmetry around the radar location of category A cases, characterized by layers of positive ZDR. The confinement of inferred anisotropic crystals to the periphery of this convective snowstorm suggests the presence of weaker updrafts there than in the core. The in situ temperature in this boundary region is approximately $-12^{\circ} \mathrm{C}$, which according to the crystal habit diagram in Fig. 2 is a region favorable for the occurrence of plate crystals, the most anisotropic hydrometeors following the discussion in section $2 \mathrm{a}$, in a possibly watersubsaturated condition. However, the aircraft measurements described in section $2 \mathrm{~d}$ suggest that the scatterers in this case could be unrimed dendrites with superlative aspect ratios. The $Z-Z D R$ scatterplot shows
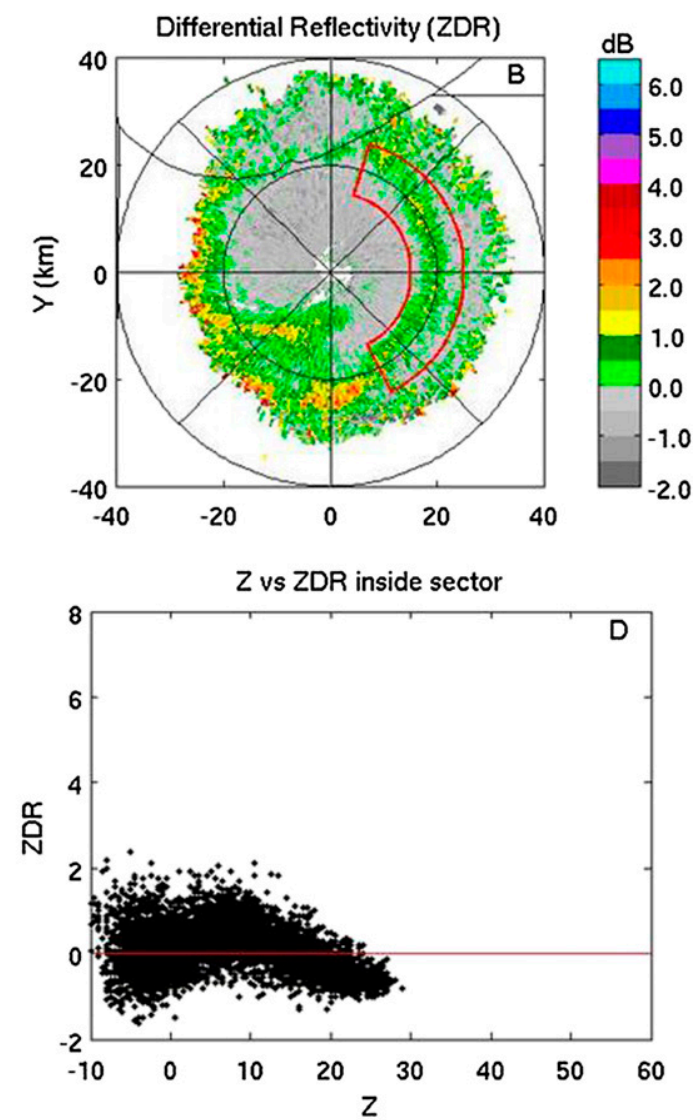

UTC 24 Feb 2010 for the $4.3^{\circ}$ PPI

a characteristic inverse relationship, suggesting the idea that the weakest reflectivity is associated with relatively isolated pristine crystals growing at ice supersaturation and without the anisotropy-diluting effects of riming and aggregation. Some tendency for negative values of ZDR is evident at the high-reflectivity end of the scatterplot. It is possible that these values are associated with conical graupel (Knight and Knight 1973; Evaristo et al. 2013), which is more prevalent in the central, stronger-updraft region of the storm.

\section{4) 0514 UTC 5 NOVEMBER 2010, $10.0^{\circ}$ PPI: CATEGORY B}

This is a warm case at the surface near the radar (above $5^{\circ} \mathrm{C}$ ), and is illustrated in Fig. 9. Convective lakeeffect rain showers are occurring at the surface but aloft the classic cap feature is observed in the ephemeral outer reaches of the showers to the south. The expected inverse relationship between $Z$ and ZDR is again noted in the scatterplot (Fig. 9d). ZDR values up to nearly $+6 \mathrm{~dB}$ are present in the analysis sector in weak reflectivity (near $0 \mathrm{dBZ}$ ) suggesting crystal plates in an environment close to water saturation. 

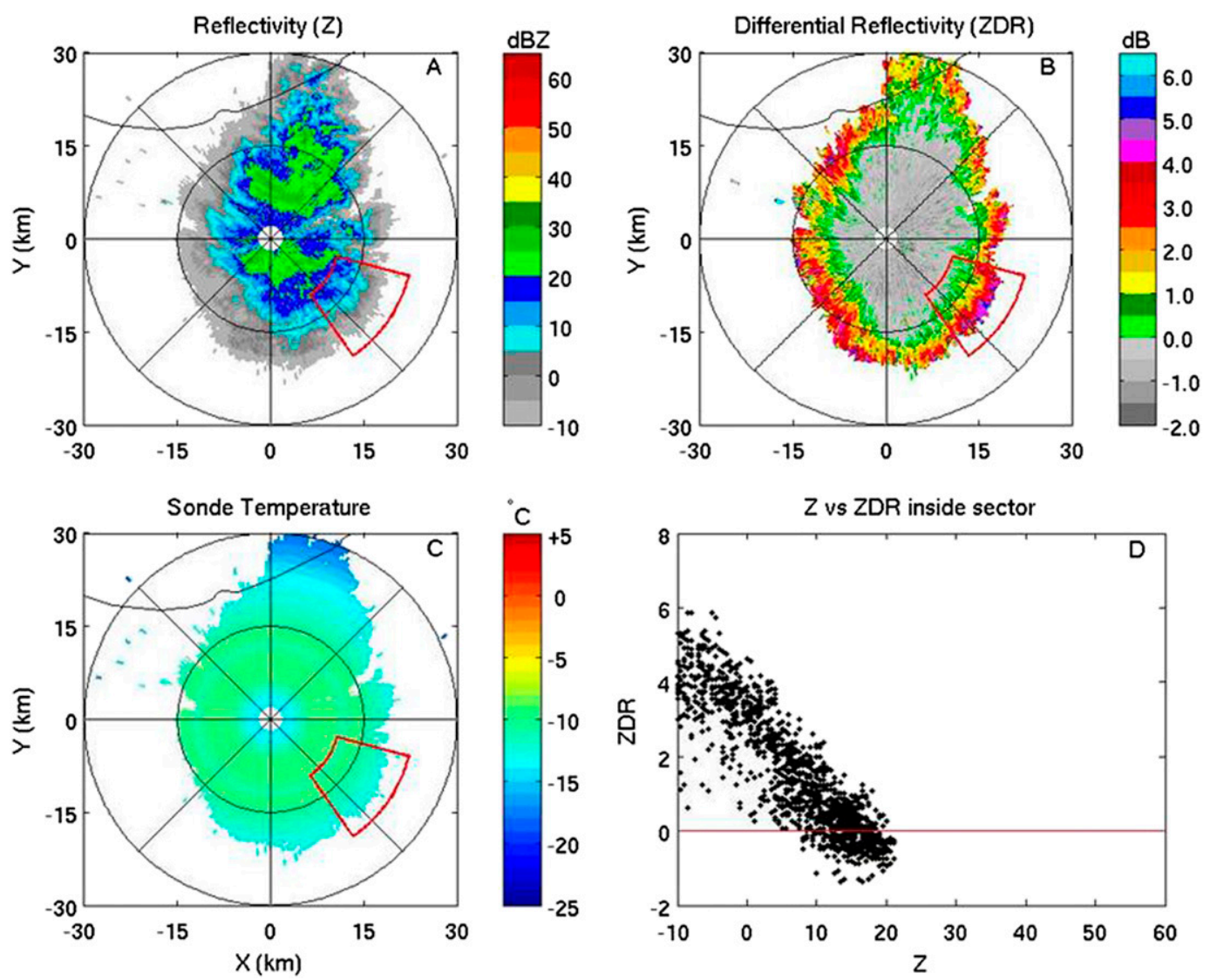

FIG. 8. As in Fig. 6, but for 1625 UTC 8 Jan 2010 for the $4.3^{\circ}$ PPI. This case exhibits a cap or edge effect on the upper boundary of the reflectivity region and is classified as category B (see text).

\section{5) 1912 UTC 1 FEBRUARY 2011, $4.3^{\circ}$ PPI: CATEGORY B}

This Groundhog Day blizzard produced Chicago's third greatest snowfall on record (20.2 in.) and its synoptic scale overlaid all of northern Indiana as well. Figure 10 illustrates the situation as the northern radar boundary of this storm approaches during the afternoon of 1 February. This leading boundary was formed by the lifting of air translating north and east along the sloping warm-frontal surface whose manifestation at ground level was still $500 \mathrm{~km}$ south of the Valparaiso C-band radar. A distinct large area patch $\left(\sim 500 \mathrm{~km}^{2}\right)$ in the northeastern radar quadrant exhibits a + ZDR anomaly reaching $+7 \mathrm{~dB}$, among the largest values observed in all storms considered. The anomalous region is also associated with an engulfment in the reflectivity field, suggesting intrusion of drier air and a possible suppression in the attainment of a water saturation condition. Like other category B cases, the strongest ZDR values are associated with the weakest reflectivities. The in situ temperatures (from $-6^{\circ}$ to $-14^{\circ} \mathrm{C}$ ) are compatible with the suggestion that crystal plates and sector plates are the dominant radar targets in the region of weaker reflectivity.

\section{d. Warm season case studies}

\section{1) 0043 UTC 27 August 2011, 8.0 PPI: CATEGORY A}

Hurricane Irene forged a path up the east coast of the United States, making its first landfall near the dual-polarization NEXRAD instrument in Morehead City (KMHX). This provided an unprecedented opportunity to study the dual-polarization signatures from within an Atlantic basin tropical cyclone. From Fig. 11, the tropical nature of the storm is evident through observations of the traditional melting-layer brightband signature in the reflectivity (Fig. 11a). At about 30-km range, a ring of near $45-\mathrm{dB} Z$ reflectivity is seen about the radar. This feature corresponds to a melting-layer altitude of around $4.2 \mathrm{~km}$ AGL. This traditional meltinglayer bright band is also evident at the same range in the differential reflectivity (Fig. 11b) as a relative enhancement (about 1-2 dB above adjacent areas). At larger range, the $+\mathrm{ZDR}$ anomaly of category $\mathrm{A}$ is seen as 

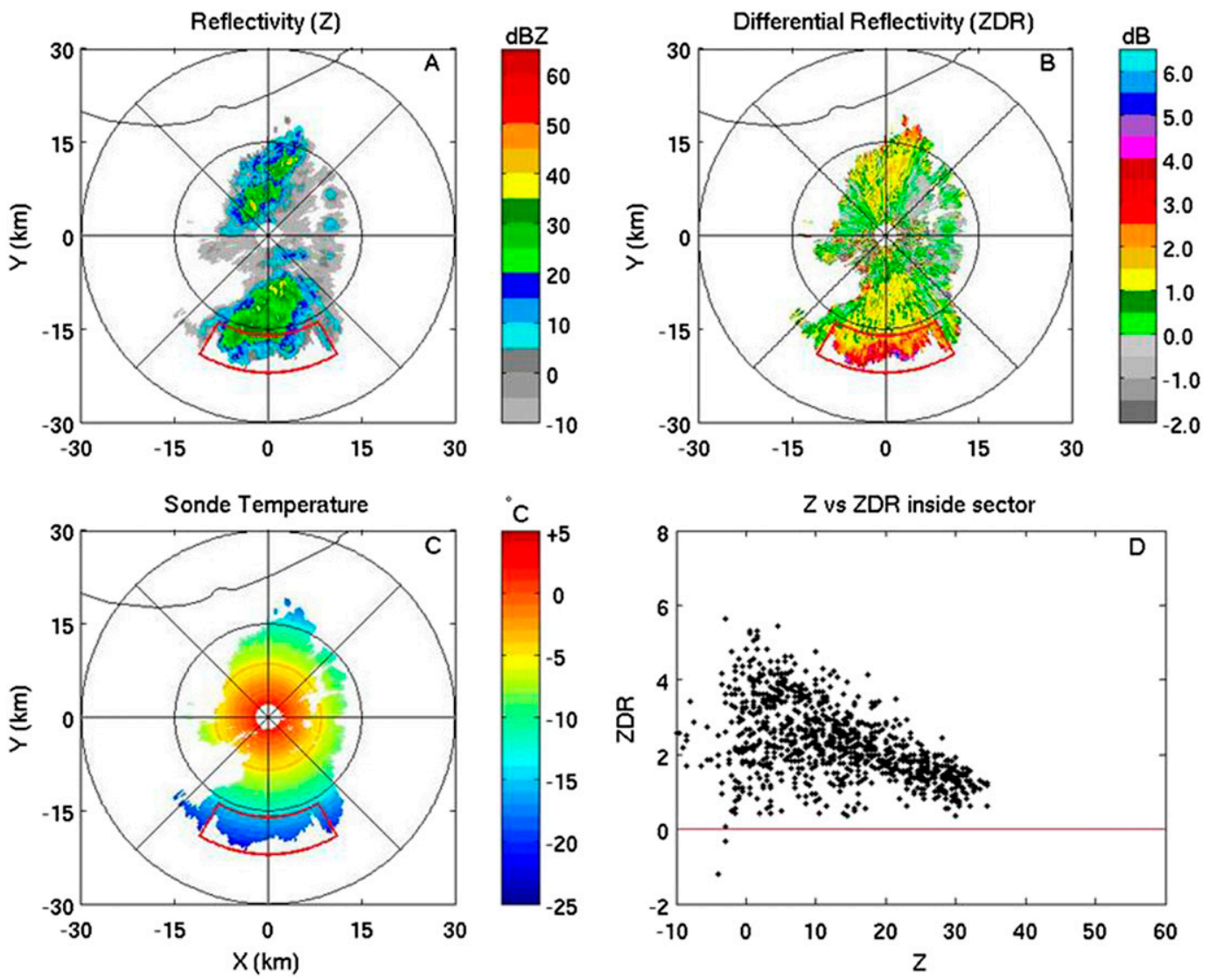

FIG. 9. As in Fig. 6, but for 0514 UTC 5 Nov 2010 for the $10^{\circ}$ PPI. This case is for the edge of rain showers and is classified as category B (see text).

a secondary enhanced ring. The multiple banding has been observed in a wide variety of situations. The + ZDR anomaly range $(\sim 55 \mathrm{~km})$ relates to an altitude near $7.9 \mathrm{~km}$ AGL. This is an altitude substantially greater than noted in winter storms, but the upper reaches of this tropical storm are likely enveloped in a snowstorm closely resembling the Indiana cases. The nature of that snowstorm is revealed in Figs. $11 \mathrm{c}$ and 11d. The + ZDR anomaly is located near $-13^{\circ} \mathrm{C}$ temperature (from the National Weather Service 0000 UTC sounding) with ZDR predominantly from +1 to $+3 \mathrm{~dB}$ and reflectivity of $10-25 \mathrm{~dB} Z$. Thus, this case shows the same category A characteristics of a water-saturated environment with dendrite crystals likely.

\section{2) 1130 UTC 3 JULY $2012,10.0^{\circ}$ PPI:} CATEGORY A

This summertime case near Seattle is associated with an occluded front running parallel to the coastline, with a band of precipitation moving onshore from the Pacific Ocean. The Seattle NEXRAD instrument (KATX) is located approximately $110 \mathrm{~km}$ from the coastline for these observations. The +ZDR bright band is most apparent in the radar PPI scans when the band is approaching and receding from the radar, with weaker manifestation when the band is directly over the radar. Figure 12 shows an example at 1130 UTC when the band is approaching the radar. The ring of positive anomaly in ZDR is well defined for only a portion $\left(\sim 130^{\circ}\right)$ of the full range of azimuth.

\section{3) 1230 UTC 31 August 2012, 8.7 PPI: CATEGORY A}

Hurricane Isaac diminished from category 1 status in the Gulf of Mexico to become a tropical depression moving up the Mississippi River valley, to within observational range of the NEXRAD in St. Louis (KLSX) on 31 August 2012. The +ZDR brightband signature showed asymmetry about the radar location, initially showing a strong signature in the southern quadrants when the main east-west-oriented band around the low pressure center was south of the radar, and then a strong signature in the northern quadrants when the band moved north of the radar. (This behavior was notably different for many of the other +ZDR brightband cases in this study, which occurred in more 

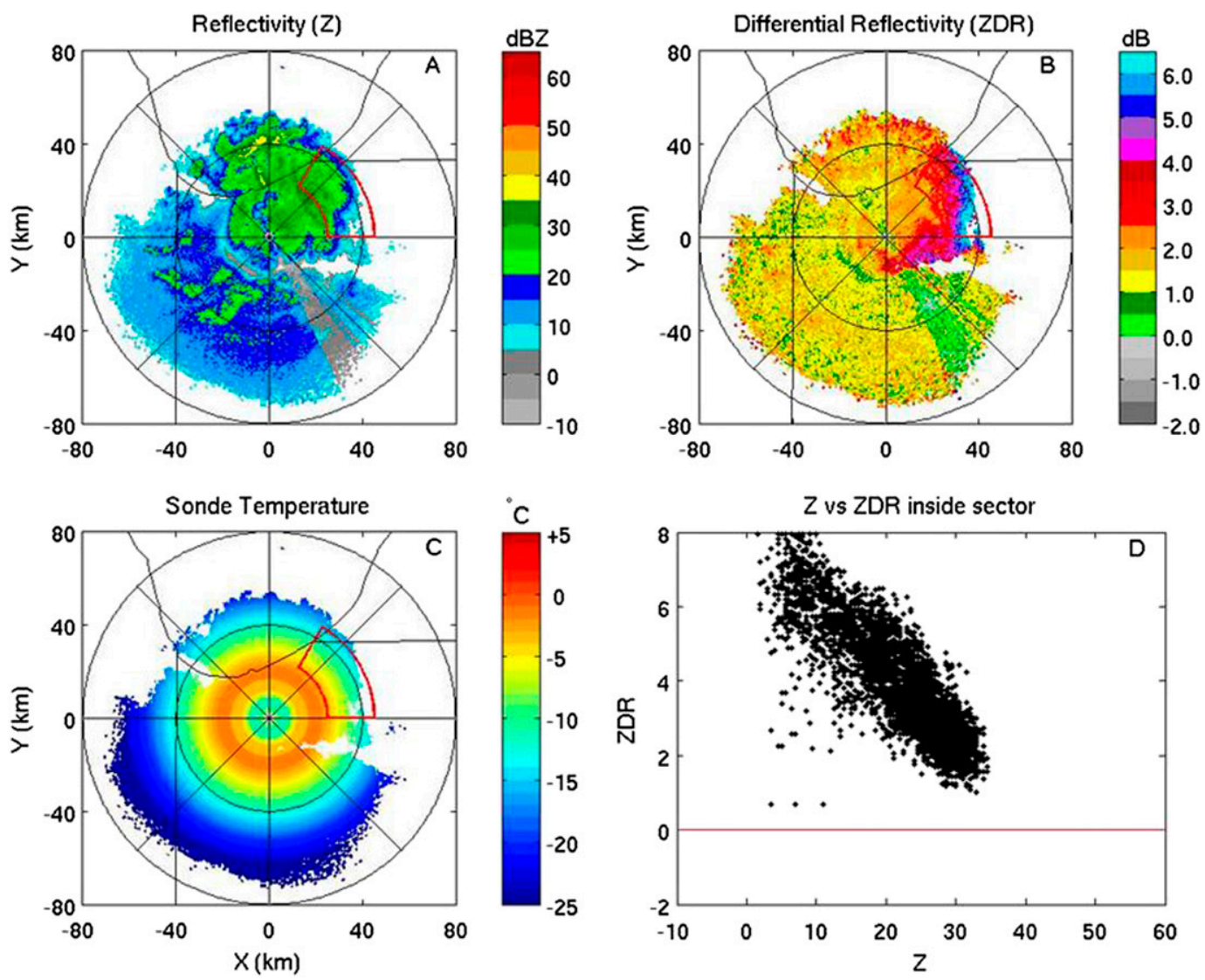

FIG. 10. As in Fig. 6, but for 1912 UTC 1 Feb 2011 for the $4.3^{\circ}$ PPI. This case is the leading edge of a snowstorm and is classified as category B (see text).

laterally homogeneous situations.) Figure 13 shows the polarimetric radar observations at 1230 UTC in the earlier configuration. The annular segment of enhanced positive ZDR in the southern quadrant is readily apparent. No lightning was detected in this large rainband during the time of these observations. Radar-measured vertically integrated liquid (VIL) values in the rainband are not larger than level $2\left(0.76-3.5 \mathrm{~kg} \mathrm{~m}^{-2}\right)$.

4) A COMPARISON OF TWO SQUALL-LINE CASES: 17 JUNE 2012 (INDIANA) AND 20 MAY 2011 (OKLAHOMA)

Two cold-frontal squall lines have been examined for the presence of $+\mathrm{ZDR}$ bright bands in the respective trailing stratiform regions: a weakly convective case on 17 June 2012 and a strongly convective case on 20 May 2011. The convective vigor has been documented with cloudto-ground flash activity from the National Lightning Detection Network and with the radar-measured VIL.

\section{(i) 17 June 2012: Weak squall line, category A}

This line developed around 0200 UTC east of a northsouth-oriented cold front in western Illinois and progressed eastward toward the Valparaiso C-band radar. At 0200 UTC the line showed lightning rates of $\sim 290$ flashes $(500 \mathrm{~km})^{-1}$ of line length in $5 \mathrm{~min}$. By $0400 \mathrm{UTC}$, the activity had diminished to $\sim 160$ flashes $(500 \mathrm{~km})^{-1}$ and by 0600 UTC the rate had decreased further to $\sim 40$ flashes $(500 \mathrm{~km})^{-1}$. By this time, the prefrontal trough had moved beyond the radar to the east, and stratiform rain dominated the radar display, and with no cloud-toground (CG) lightning detections. The radar-measured VIL in the leading convection dropped from values of 5 and $6\left(12+\mathrm{kg} \mathrm{m}^{-2}\right)$ at the earlier times $(0200$ and $0400 \mathrm{UTC})$ to values of $3\left(3.5-6.9 \mathrm{~kg} \mathrm{~m}^{-2}\right)$ at $0600 \mathrm{UTC}$. Figure 14 shows evidence for a + ZDR bright band on the $19.5^{\circ}$ tilt at $0608 \mathrm{UTC}$, with maximum + ZDR values of $3.7 \mathrm{~dB}$.

(ii) 20 May 2011: Strong squall line, no category $A$ or $B$

This prefrontal Oklahoma case documented with the NEXRAD instrument in Norman (KOUN) occurred during the morning of 20 May as a remnant of coldfrontal convection the day before. At 1350 UTC, the trailing stratiform region extended $\sim 180 \mathrm{~km}$ behind the 

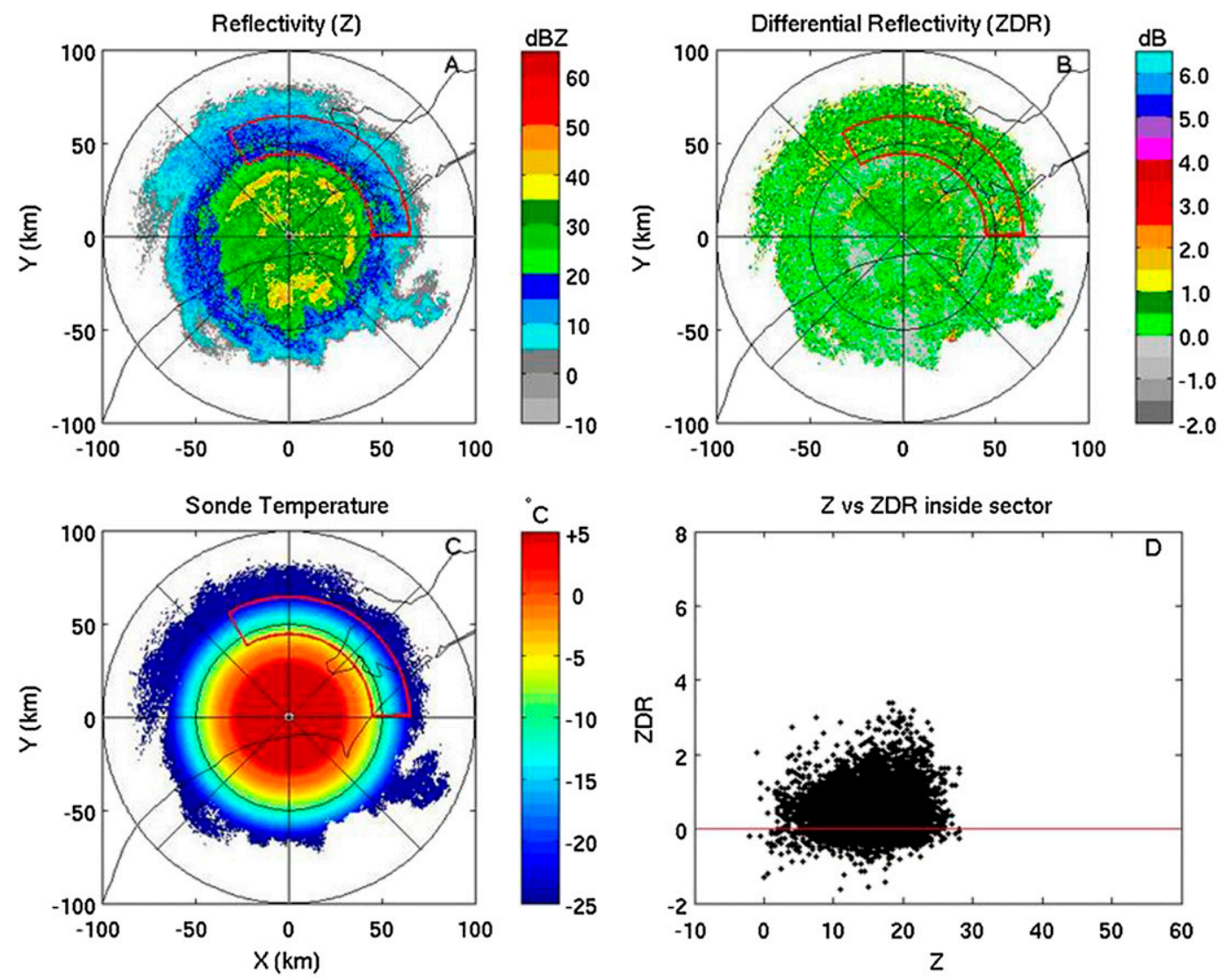

FIG. 11. As in Fig. 6, but for Hurricane Irene data from the KMHX polarimetric radar and a local-release weather sonde at 0043 UTC 27 Aug 2011 for the $8^{\circ}$ PPI. This case is a "snowstorm aloft" in the hurricane and is classified as category A (see text).

line of leading convection. Despite its occurrence early in the diurnal cycle, the lightning activity and VIL values showed a markedly more vigorous storm than the 17 June case previously described. At 1350 UTC, the line exhibited $\sim 230$ flashes $(500 \mathrm{~km})^{-1}$ of line length in $5 \mathrm{~min}$, with VIL values of 5 and 6 in the leading line and values of 2 and 3 in the stratiform region. The lightning production in the entire stratiform region was showing $\sim 10 \mathrm{CG}$ flashes in $5 \mathrm{~min}$. Figure 15 shows the KOUN polarimetric radar data for this case. No evidence whatsoever can be seen for any +ZDR brightband features at altitudes above the conventional radar bright band, whose circular feature is well defined.

\section{e. In situ temperature measurements at $+Z D R$ brightband elevations}

Proximity thermodynamic soundings from the C-band radar site in Valparaiso have been used wherever available to record the in situ temperature at the height of the radar-observed + ZDR bright bands (category A). These soundings were most often available for the winter storm cases documented in Indiana with the C-band radar and were made from the radar site at the times of the observed bright bands. A histogram of such measurements is shown in Fig. 16a. The temperature values are fairly tightly distributed between $-9^{\circ}$ and $-16^{\circ} \mathrm{C}$, with a mean value of $-12.3^{\circ} \mathrm{C}$. These results show excellent agreement with those of Sauvageot et al. (1986) (Fig. 16b), for which in situ temperatures were checked whenever K-band polarimetric radar observations showed ZDR values exceeding $2 \mathrm{~dB}$. This criterion is consistent with the definition of category $\mathrm{A}$ in the present study. Also, as noted by Sauvageot et al. (1986), the ice crystal growth rate is broadly at a maximum in this observed range of temperature because the maximum contrast in vapor pressure over water and over ice to drive the Bergeron process (Byers 1965).

Examination of the crystal habit diagram (Bailey and Hallett 2009, Fig. 2) on the basis of diffusion chamber measurements of ice crystal growth shows a prevalence for flat, thin crystals over this same range of observed in situ temperatures, but with a notable humidity dependence. In water-saturated conditions, dendritic 

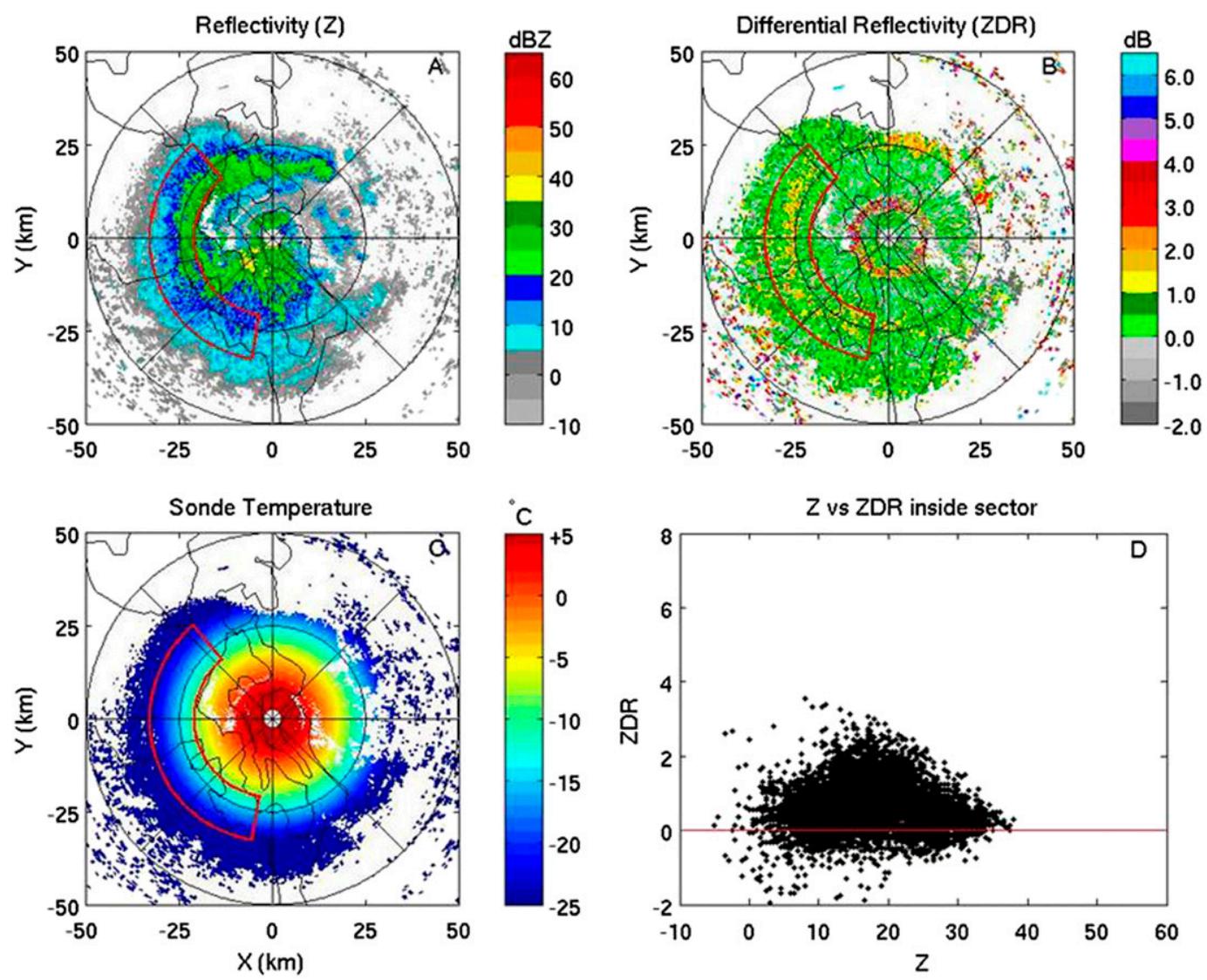

FIG. 12. Similar to Fig. 6, except that (c) shows model temperatures for the grid bin that is nearest to the radar. The data are from the KATX S-band polarimetric radar and RAP 13-km model temperatures at 1130 UTC 3 Jul 2012 for the $10.0^{\circ} \mathrm{PPI}$. This case is a summertime event with a band of precipitation moving onshore from the Pacific Ocean and is classified as category A (see text).

crystals are prevalent, but hexagonal plates are possible at water subsaturation. (Careful examination of Fig. 2 shows the presence of hexagonal plates both above and below the sloping red line.) These crystal types, when oriented horizontally by gravity, are the most anisotropic hydrometeors to polarimetric radar (Hogan et al. 2002), giving rise to the higher positive ZDR. The relative humidity measurements in routine thermodynamic soundings are unfortunately not sufficiently accurate to distinguish water from ice saturation. Further, the temporal and spatial availability of soundings is lacking. Thermodynamic soundings generated from meteorological models address these aspects, but not the concerns regarding saturation states. Consistent with Kennedy and Rutledge (2011), we are interpreting the more modest + ZDR values (category A) as originating in the growth of dendritic crystals in water-saturated conditions. No interpretation is implied regarding supercooled water, its presence or sustainment, based on temperature alone. In situ aircraft missions are paramount in helping to further describe and quantify the microphysics occurring within.

\section{Discussion}

This study places new radar polarimetric observations of a wide range of winter and summer storms within the broader context of earlier laboratory studies on crystal habits (Bailey and Hallett 2009), on earlier field observations in which crystal habits were observed in situ along with simultaneous ZDR measurements (Wolde and Vali 2001a), and on aircraft observations of in situ conditions also under surveillance by polarimetric radar. The new observations find consistency with warm season studies of stratiform precipitation systems with deep ice regions aloft (Bader et al. 1987; Moisseev et al. 2009; Andric et al. 2013), where local snowstorms are also present. In all of these systems, the most pronounced positive anomalies in differential reflectivity can be placed into categories A and B (Table 1) relating to ice and liquid water saturation states and the qualitative inference for the presence of supercooled water.

\section{a. Physical interpretation of categories $A$ and $B$}

The positive values of differential reflectivity found in the various case studies can be broadly categorized as A 

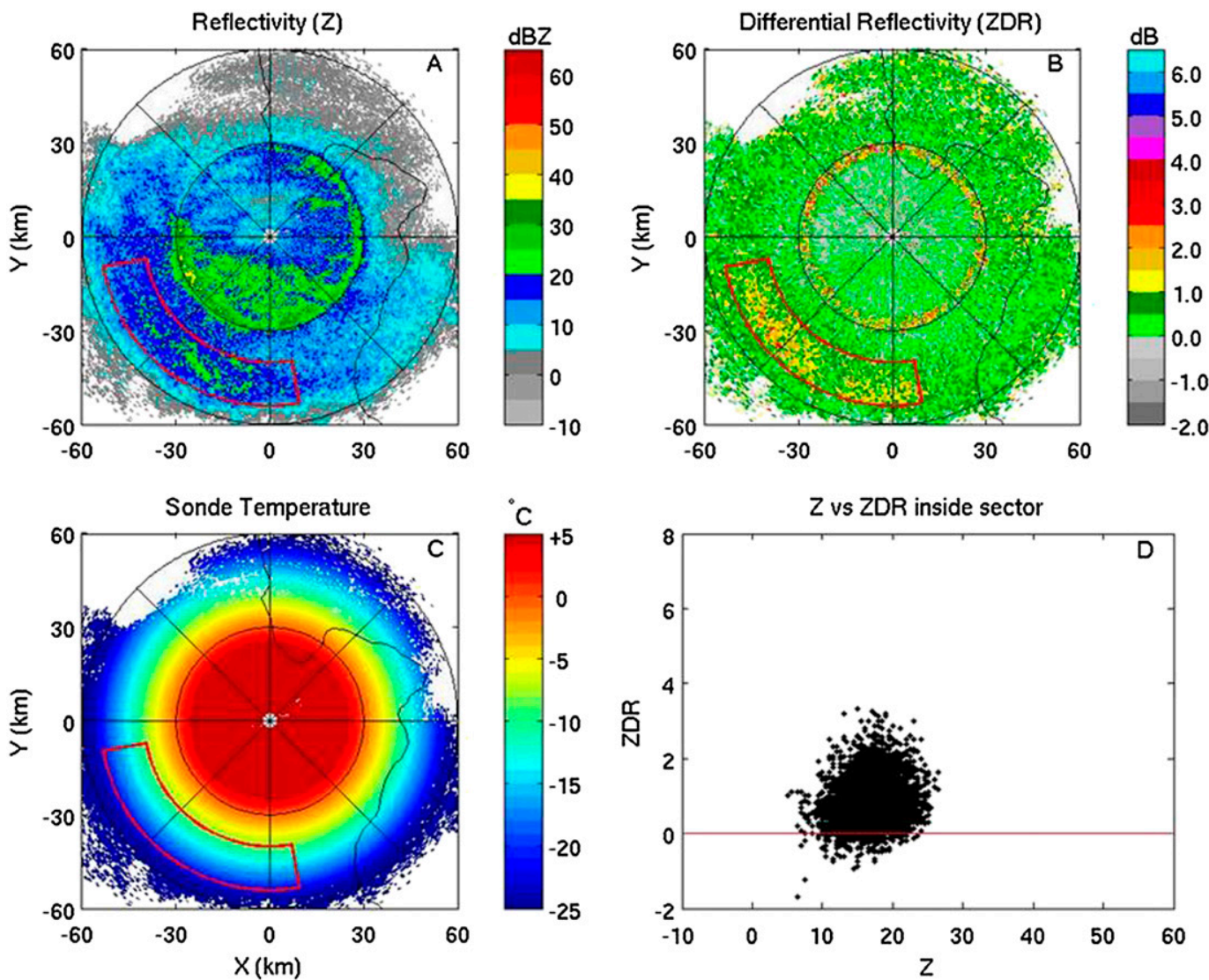

FIG. 13. As in Fig. 12, but for data from the KLSX S-band polarimetric radar and RAP 13-km model temperatures at 1230 UTC $31 \mathrm{Aug} 2012$ for the $8.7^{\circ} \mathrm{PPI}$. This case is a tropical depression from the remnants of Hurricane Isaac and is classified as category $\mathrm{A}$ (see text).

or B. Category A involves extensive layers of modest positive ZDR, referred to here as + ZDR bright bands and characterized by moderate reflectivity $(20-30 \mathrm{dBZ}$ typically). Category B cases exhibit the most extreme positive values of ZDR (8-9 dB), predominant along the edges of the general reflectivity pattern and not generally showing the extensive continuity in layers more typical of category A, and characterized by the weakest values of reflectivity (from -10 to $+10 \mathrm{dBZ}$ ), often near the noise floor of the radar. In the original interpretation of these two categories (Williams et al. 2011), when only snowstorms had been examined, we were inclined to identify a distinct crystal class with each category: dendritic crystals for category A (following Kennedy and Rutledge 2011) and hexagonal plates for category B. The view in the present study has been amended, based on the aircraft measurements discussed in section $2 \mathrm{~d}$, the apparent scarcity of hexagonal plates in natural clouds, and the recent work of Moisseev et al. (2012) on embryonic aggregates that may also achieve aspect ratios exceeding 10 to 1 . We can verify on the basis of recent additional aircraft measurements that hexagonal flat-plate crystals may be more common than previously believed (Williams et al. 2013a).

Let us begin with the evidence for the largest positive ZDR signatures in category B. According to theoretical calculations, the most anisotropic crystal shape is the thin hexagonal plate, followed by sector plates (Hogan et al. 2002). The calculations show increasing +ZDR values for increasing aspect ratio of flat crystals. Observations by Auer and Veal (1970) show increasingly large aspect ratios with crystal size, a favorable circumstance for dual-polarization radar detection. For aspect ratios reaching 50 to 1 (Auer and Veal 1970), the theoretical values for ZDR reach $+9 \mathrm{~dB}$ for plate crystals, near the upper limit for category B observations. Perhaps the most important evidence for interpreting category B comes from Wolde and Vali (2001a), who identified sector plates in their in situ aircraft observations with the largest $+\mathrm{ZDR}$ values $(+7 \mathrm{~dB})$ in their onboard W-band radar observations. Furthermore, in the crystal habit diagram of Bailey and Hallett (2009), plates are prevalent at water subsaturation in the observed temperature range of our measurements (Fig. 16) 

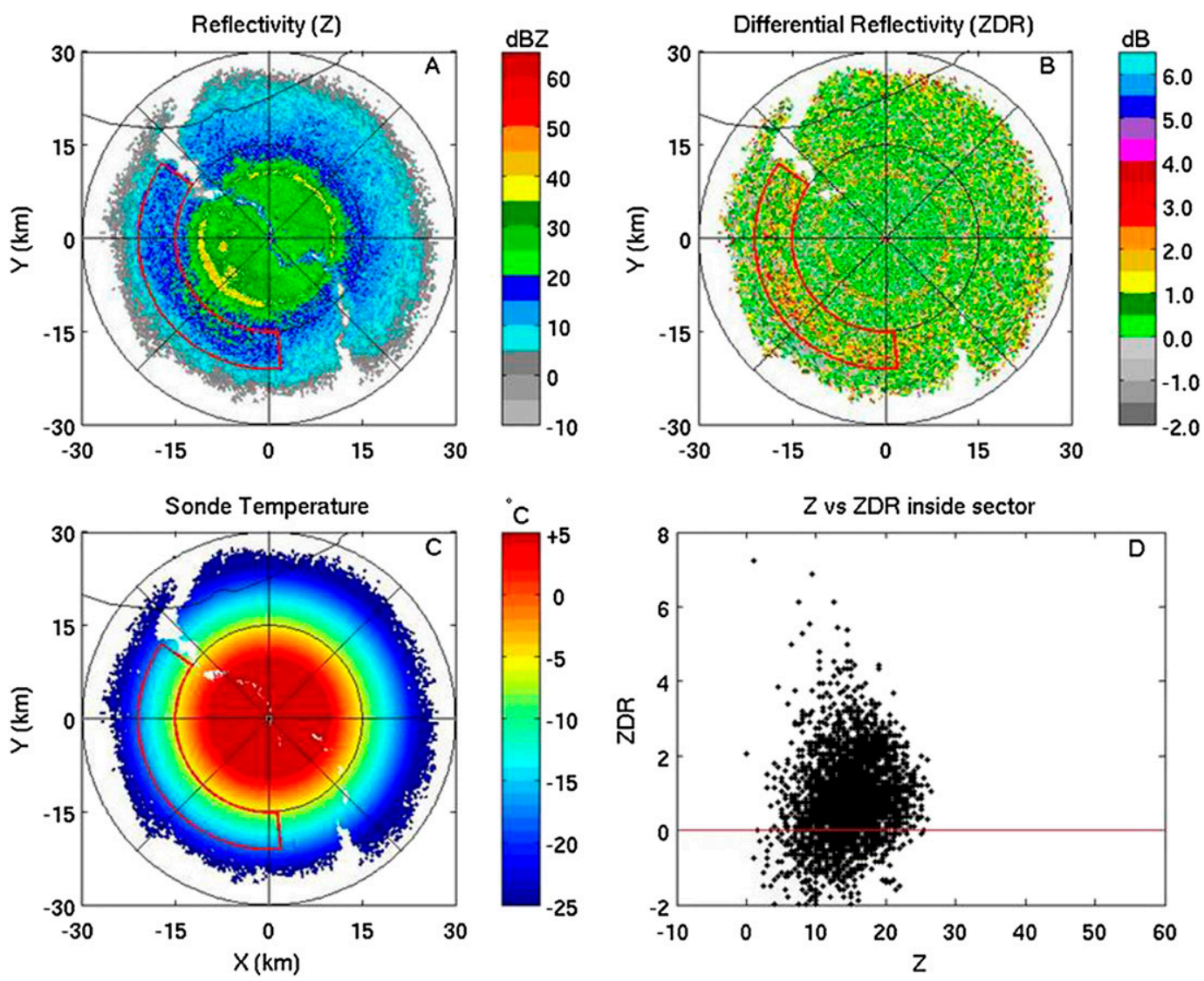

FIG. 14. As in Fig. 12, but for data from the Valparaiso University C-band polarimetric radar and RAP 13-km model temperatures at 0608 UTC 17 Jun 2012 for the $19.5^{\circ}$ PPI. This case is behind a departing squall line with weakening convection and is classified as category A (see text).

and water-subsaturated conditions are plausible near the edges of the reflectivity regions, when category B was prevalent. This water-subsaturated "edge" condition is also manifest in laboratory experiments (Foster and Hallett 2002, 2008) in the cold box (Schaefer and Day 1981), showing the presence of hexagonal plates primarily in the top boundary of the cold box cloud, across a range of temperatures consistent with the diffusion chamber measurements (Bailey and Hallett 2009), where water-subsaturated conditions are most likely. If these plates were rimed, they would not act as tiny mirrors in the laboratory experiments (Foster and Hallett 2008). On the other hand, the Bailey-Hallett diagram shows that hexagonal plates are found on both sides of the water saturation line in Fig. 2, unlike needles and dendrites that are clearly associated with water-saturated conditions.

Despite these lines of evidence in favor of hexagonal plates as the origin of category $\mathrm{B}$, the aircraft observations under dual-polarization radar surveillance described in section $2 \mathrm{~d}$ showed the presence of large dendritic crystals characterized by $+7 \mathrm{~dB}$ (among the largest values in the various $Z$-ZDR diagrams for the category B case studies), with no indications of plate crystals (Fig. 4). Furthermore, for reasons not currently understood, plate crystals are scarce in aircraft observations in general (Korolev et al. 1999). It must be noted, however, that a most recent dual-polarization-radar-guided icing mission during winter 2013, still in incipient analysis (Williams et al. 2013a), did reveal notable regions of hexagonal plates with attendant positive ZDR values consistent with category $\mathrm{B}$. The supercooled water concentrations were intermittent at this time. Is it possible hexagonal plates have eluded prior studies because of conditions (truly not present) or opportunity missed (truly present)?

In summary for category B, unrimed flat dendritic crystals are the likely prevalent scatterer, but plates and sector plates remain possible candidates at least under certain quiescent conditions, as recently discovered in situ. The embryonic aggregates named by Moisseev et al. (2012) may also serve here, but only if they consist of linked dendrites whose effective aspect ratio exceeds 10 to 1 . Such particles have been noted in weak 

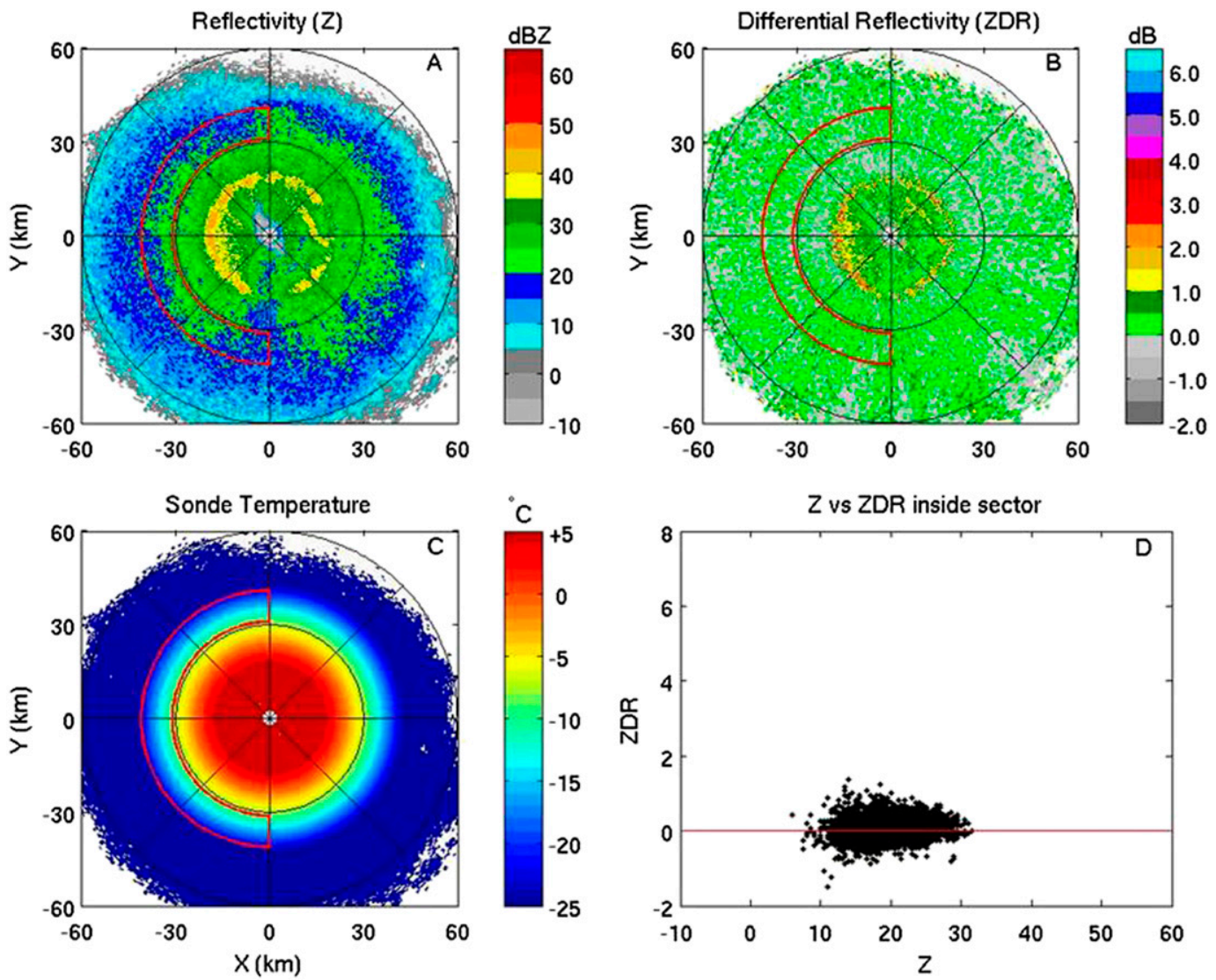

FIG. 15. As in Fig. 12, but for data from the KOUN S-band polarimetric radar and RAP 13-km model temperatures at 1350 UTC 20 May 2011 for the $10.0^{\circ} \mathrm{PPI}$. This case is a strong prefrontal squall line and does not show any evidence of a +ZDR bright band.

snowstorms in New England, with weak radar reflectivity $(<10 \mathrm{~dB} Z)$.

In contrast with category $\mathrm{B}$, the category $\mathrm{A}$ cases involve layers of positive ZDR that lie more deeply within the reflectivity boundaries of storms. The radar evidence for this assertion is the partial or complete rings of ZDR anomaly in the PPI scans, as in Figs. 6, 7, and 12. (In contrast, a PPI scan that intersects the boundary of the detectable radar echo, as for example in Fig. 10, shows a marked departure from circular symmetry in the +ZDR feature and is by definition an "edge" case of category B.) An important implication accompanying the internal nature of category $A$ is the virtual guarantee for greater cloud depth above the height of the $+\mathrm{ZDR}$ bright band than for category $B$ return at the cloud edge and cloud top. The aggregation of anisotropic crystals in the upper layer can then serve to dilute the positive signal in ZDR, since even embryonic aggregates may be less anisotropic than single thin planar crystals (Moisseev et al. 2012).

In contrast with the conventional radar bright band at $0^{\circ} \mathrm{C}$ with a vertical thickness of a few hundred meters, the + ZDR bright bands documented here show vertical extents up to $1 \mathrm{~km}$. Whereas crystal habit diagrams [several are shown in Bailey and Hallett (2009, their Fig. 2)] show a $\sim 3^{\circ} \mathrm{C}$ temperature interval (centered on $-14^{\circ} \mathrm{C}$ ) for the presence of dendritic crystals, the observed temperature range for the + ZDR anomalies is at least 2 times this value, suggesting that flat crystals other than dendrites alone are responsible for the radar signatures. Closer inspection of crystal habit diagrams shows that a larger temperature interval is consistent with the + ZDR bright bands observed. At conditions colder than the mean temperature (approaching $-20^{\circ} \mathrm{C}$ ), one finds hexagonal plates below the water saturation line and plate dendrites (such as P2a, P2b, $\mathrm{P} 2 \mathrm{c}$, and P2d in standard crystal identification charts) above likely yielding similar radar returns. At the warmer end (around $-10^{\circ} \mathrm{C}$ ), plate crystals seem to straddle the water saturation condition. Interestingly, +ZDR bright bands have been observed at just-below-freezing conditions in early and late season storms. At these temperatures (around $-4^{\circ} \mathrm{C}$ ), the crystal habit diagram shows plates as being the dominant form. As with category B, 


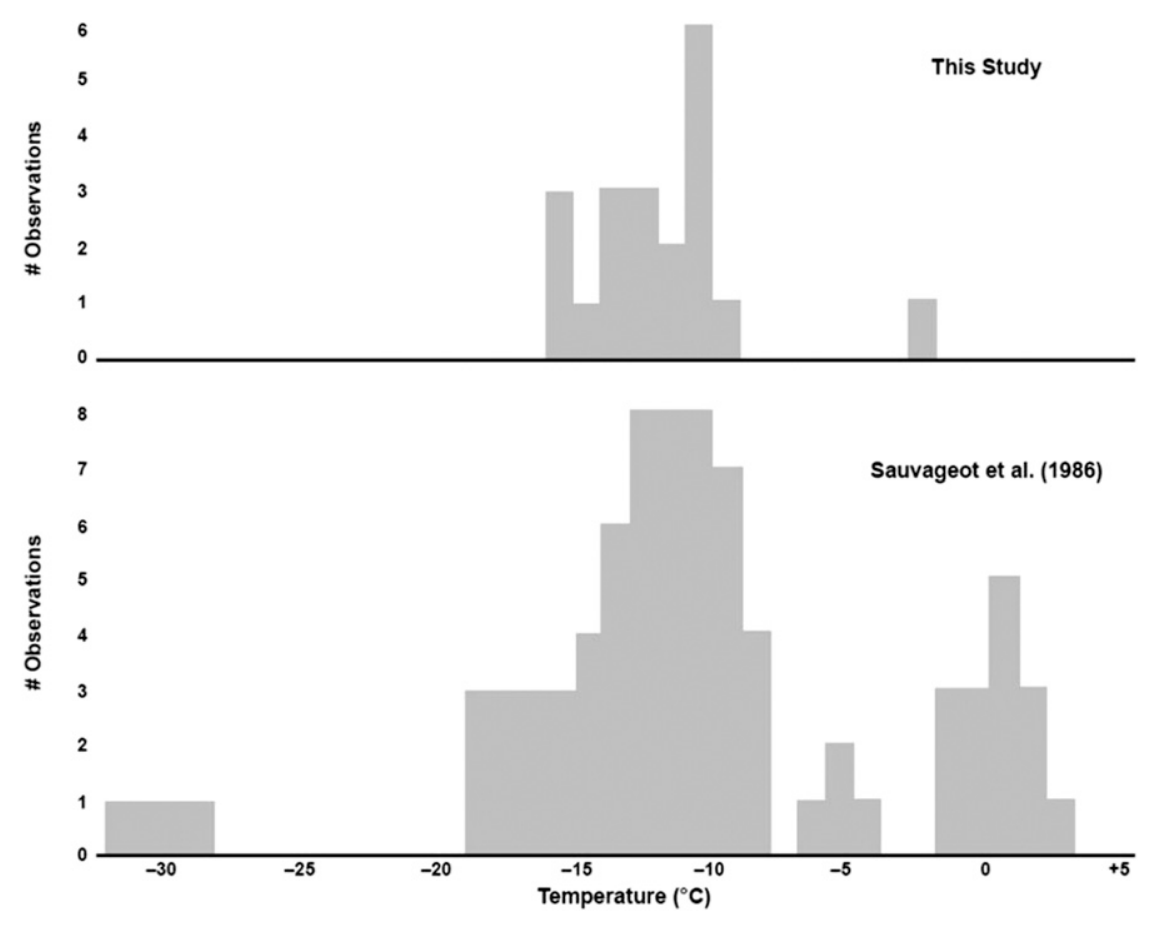

FIG. 16. (a) Distribution of in situ temperatures where maximum positive ZDR values are found in radar volume scans and (b) distribution of temperatures found in an earlier study by Sauvageot et al. (1986).

more is to be learned about the crystal possibilities with category A +ZDR bright bands. What is clear is the prevalence of this feature in PPIs suggests the need for in situ aircraft probing and developing the connection to supercooled water.

\section{b. The possible role of an electric field on differential reflectivity}

The systematic ice particle alignments that provide for the positive values of ZDR prevalent in this study are determined primarily by gravity and aerodynamic forces. Needles and flat crystals orient with their long axes perpendicular to gravity to account for the radar response. However, it is well known that the electric field in clouds can also influence the orientation (or canting angle) of crystals with oblate and prolate shapes (Weinheimer and Few 1987; Foster and Hallett 2002; Metcalf 1993, 1995, 1997; Krehbiel et al. 1996). Since the preferred mechanisms for creating the electric field are based on gravitational separation of oppositely charged hydrometeors, the electric field in clouds tends to be aligned with gravity. [See also polarimetric radar evidence in thunderstorms presented by Krehbiel et al. (1996).] And since the minimum energy configuration for oblate and prolate crystal shapes is an alignment of their long axes with the electric field, ice crystal orientations tend to be perpendicular to the orientation with gravity alone. This is to say that strong negative values of differential reflectivity are expected in the presence of ice crystals in a strong vertical electric field.

How strong is strong? The competition between aerodynamic and electrical torques has been thoroughly investigated by Weinheimer and Few (1987). For flatplate crystals with diameters $D$ of order $30 \mu \mathrm{m}$, the electric field magnitude required for orientation is of order $10 \mathrm{kV} \mathrm{m}^{-1}$, about 100 times the magnitude of the earth's fair weather field. This alignment condition has been verified in laboratory experiments by Foster and Hallett (2002). But for larger crystal sizes $(\sim 600 \mu \mathrm{m})$ that have grown by vapor diffusion over longer times and that begin to be important for radar backscatter $\left(\sim D^{6}\right)$, electric fields with magnitude $100 \mathrm{kV} \mathrm{m}^{-1}$ are required. This value is within a factor of 3-5 of the magnitude necessary to initiate lightning (Marshall et al. 1995).

With this quantitative information as background, it is of interest to speculate about the presence of strong electrification in the collection of storms that constitute the present study. The only case study storms for which lightning was documented were the summer squall lines. This observation is consistent with a large body of other work (Chauzy et al. 1980; Engholm et al. 1990; Williams and Ecklund 1992) that the stratiform region of summer 
squall lines can exhibit a strong electric field at the ground $\left(\sim 10 \mathrm{kV} \mathrm{m}^{-1}\right)$ and fields aloft sufficient for lightning initiation. In contrast, snowstorms with moderate and steady snowfall rates $\left(\sim 1 \mathrm{~cm} \mathrm{~h}^{-1}\right)$, and little if any riming, are only weakly electrified $\left(\sim 1 \mathrm{kV} \mathrm{m}^{-1}\right.$, an order of magnitude over fair weather fields). No lightning was observed in the snowstorm periods we have categorized as A and B. The evidence for systematic positive ZDR in all the snowstorms and warm season stratiform systems documented here offers strong support that the vertical electric fields they contain are not sufficient to reorient ice crystals and change the sign of ZDR. Indeed, to build electric fields of the magnitude needed for lightning initiation, one needs an active riming process and the formation of graupel particles (Takahashi 1978; Williams 1989). This vigorous riming process may destroy the anisotropic scatterers needed for an appreciable effect on ZDR in the first place. Further studies of the electric field in storms exhibiting similar anomalies in ZDR are needed to verify this prediction.

\section{c. Contrasting the stratiform regions of warm season squall lines with winter snowstorms}

Winter snowstorms and the cold upper portions of warm season trailing stratiform regions share common features: mesoscale ascent at speeds generally less than $1 \mathrm{~m} \mathrm{~s}^{-1}$, precipitation rates of order $1 \mathrm{~mm} \mathrm{~h}^{-1}$, and large lateral extents of tens to hundreds of kilometers. From the cloud microphysical standpoint, if oriented crystals and embryonic aggregates can produce positive ZDR signatures in winter storms, the same is expected in their warm season counterparts. The gentle ascent will guarantee the ice supersaturation needed for the growth of anisotropic, gravity-oriented crystals. But while the trailing stratiform region of the weak, low-lightning rate (at the time of the stratiform ZDR observations) squall line on 17 June 2012 shows a +ZDR category A characteristic, no such feature is discernible in the strong, lightning-active Oklahoma case on 20 May 2011.

This tendency for an absence of a category A feature in trailing stratiform regions of active squall lines is supported by other earlier findings. One of the first polarimetric radar studies of a mesoscale convective system (Zrnić et al. 1993) showed only weak $(+0.2 \mathrm{~dB})$ differential reflectivity above the melting level, with no notable signature in the range of temperature most favorable for anisotropic ice crystals documented in Fig. 16. Furthermore, during a study of vigorous West African squall lines during the Africa Monsoon and Multidisciplinary Analysis (AMMA) campaign (Russell et al. 2010) and the Meghatropiques 2010 field program in Niger, no +ZDR brightband features were noted with the Xport radar (M. Gosset 2010, personal communication).

Two possible explanations for the disappearance of category $\mathrm{A}$ in the trailing stratiform region suggest themselves. First, the leading deep convection is known to deliver ice particles to the trailing stratiform region, and active riming in strong updrafts is known to predominate in that region. (No such scenario is present in the winter storm case, which commonly involves ascent on a warm-frontal surface to produce all the ice particles.) Both rimed and heavily aggregated particles will generally be substantially less anisotropic than pristine crystals, as was the case in the aircraft measurements reported in section $2 \mathrm{~d}$, and so may greatly dilute or erase any positive ZDR signature. Second, as noted in the previous section on electric field effects, strong fields may be present in the trailing stratiform region of active squall lines, and so the orientation of such particles in directions other than those dictated by gravity alone may also dilute the +ZDR effects. Further studies of squall lines under polarimetric radar surveillance with in situ measurements of microphysics and electric field are needed to verify this explanation.

\section{d. Implications for icing hazards}

A key microphysical distinction with obvious practical importance for aircraft icing is the inferred presence of liquid water in category $\mathrm{A}$ and its required virtual absence in category B. This study has shown that category A is a common occurrence in snowstorms (particularly those of the warm-frontal variety) in northern Indiana, and in other warm season stratiform cases. The presence of the category A + ZDR bright band with inferred supercooled water in cloud layers extending for tens and hundreds of kilometers in winter storms is of obvious concern to aviation. With a network-wide polarimetric capability, such layers are increasingly evident in NEXRAD displays throughout the continental United States, and so it is essential that aircraft measurements with sensitive detection capability for cloud water are carried out in such layers to verify the association between layered anomalies in ZDR and the possible icing hazard. Category A involves a rather delicate balance between having sufficient liquid water to guarantee water saturation and consequently dendrite crystals, but not having so much water that the dendrite anisotropy is diluted by riming. Both Wolde and Vali (2001a) and Takahashi (2010) have identified conditions of water saturation when the cloud droplets were too small for riming.

The theoretical calculations from Korolev and Mazin (2003) illustrated in Fig. 3 show that thresholds in updraft speed must be crossed to attain the category A condition, and that plausibly smaller ascent speeds on storm radar 
edges are needed for category B. These predictions are fundamental for the assessment of icing hazards in conditions of ascent, but unfortunately the key parameters (updraft and $\mathrm{Nr}$ ) are not accessible to remote observations. Figure 3 shows that the larger the ice crystal parameter $\mathrm{Nr}$ is, the larger is the updraft threshold, consistent with the picture that the ice particles are sinks for the water vapor and that the updraft serves to maintain the supersaturation by adiabatic expansion. In a few cases, in situ aircraft measurements of $\mathrm{Nr}$ are available in cloud regions under surveillance for differential reflectivity (Bader et al. 1987; Wolde and Vali 2001a,b; Hogan et al. 2002), and in which evidence for category $\mathrm{A}$ is present. The measured values fall in the range of $2-5 \mathrm{~cm}^{-3} \mu \mathrm{m}$, as indicated by the grayshaded region in Fig. 3, requiring updraft speeds of the order of $0.1 \mathrm{~m} \mathrm{~s}^{-1}$ for the category A condition with supercooled water (for an in situ temperature of $-15^{\circ} \mathrm{C}$ ). Although aircraft measurements of ascent speed in the range of $<1 \mathrm{~m} \mathrm{~s}^{-1}$ are difficult to achieve by any observational method, those profilers at long wavelength that backscatter energy from the air itself are probably best suited. Within this context, it is interesting to note that updraft speeds with a 50-MHz profiler in the ice regions of stratiform anvils in mesoscale convective systems are in the range of 0.1-0.2 $\mathrm{m} \mathrm{s}^{-1}$ (Williams and Ecklund 1992; Cifelli and Rutledge 1994). Good measurements of ascent speeds in snowstorms are not presently known to us but are essential in assessing icing hazard from first principles. More attention should be given to quantifying warm-frontal slopes together with upslope winds for the purpose of determining the magnitude of the vertical ascent in snowstorms.

One reviewer asked about possible pilot reports of aircraft icing for the various cases examined here, as a check on the dual-polarization inferences about supercooled water. Unfortunately, no intersecting PIREPs could be found.

\section{$e$. The importance of accuracy in the measurement of differential reflectivity}

The key polarimetric signatures of categories A and B in this paper are on the order of $+1 \mathrm{~dB}$ and greater. Their successful detection therefore requires an absolute accuracy in ZDR on the order of a few tenths of decibels. As noted in section 3a, this accuracy could be monitored with the C-band radar in Valparaiso by performing periodic checks with measurements on rain at vertical incidence. Such measurements are unfortunately not possible with the newly configured polarimetric NEXRAD instruments. The initial objective of $0.1 \mathrm{~dB}$ for accuracy (Zrnić et al. 2010) in ZDR in the NEXRAD polarimetric upgrade will serve the hydrometeor classification algorithms well, but currently available evidence shows that this degree of accuracy has not been achieved. Calibration of the KOUN radar with isotropic metal spheres in October
2011 showed a ZDR offset of $-0.5 \mathrm{~dB}$ (Williams et al. 2013b). Furthermore, a substantial number of intercomparisons on weather targets in common between NEXRAD sites have shown differences in ZDR to be as large as $1 \mathrm{~dB}$. Further efforts (Cunningham et al. 2013) are needed to bring all radars into good absolute calibration.

\section{Summary}

The impetus for this study of the interpretation of dual-polarization parameters is to support development of an automated, radar-based icing hazard product for aviation from the NEXRAD network. Observations of winter storms with the Valparaiso University polarimetric C-band radar and, recently, with the dual-polarization NEXRAD observations from a number of warm season stratiform systems demonstrate the potential to glean valuable clues about icing hazards. Importantly, the observations have been consistent between radar platforms and with the foundational tenets of cloud and precipitation microphysics.

Two icing-hazard-related categories were described. Category A, the +ZDR brightband anomaly, represents a potential icing hazard where primarily dendritic crystals grow in a water-saturated environment (with coexisting supercooled water) at temperatures between $-10^{\circ}$ and $-20^{\circ} \mathrm{C}$. The measured ZDR documented in many situations is more consistent with the occurrence of dendrites than hexagonal flat plates. Category B, predominantly in the "caps" or edges of storms, represents a region without aircraft icing hazard where high-aspect-ratio crystals and embryonic aggregates can grow by diffusion in the absence of supercooled water (as shown by the absence of riming in the aircraft observations), but also in the same general temperature range as in category A. More recent aircraft measurements (Williams et al. 2013a) have shown intermittent supercooled water in edge regions characterized by the largest values of $+\mathrm{ZDR}$, suggesting a condition close to water saturation.

The findings in these regions with exceptional + ZDR values to date suggest a coarse ability to confidently distinguish regions with icing from those without icing within the confines of a radar volume. Theory and empirical results from controlled environments identify the key factors for segregating these regions to be the combination of vapor density over water and ice, updraft speed and its sustainment, temperature, and ice nuclei concentration. The dual-polarimetric parameters reflect the condition of that combination but do not directly measure any of them. In situ evidence suggests the icing hazard might be more accurately portrayed as a blotchy, dynamic environment rather than a laminar, homogeneous one. 
The challenge ahead is to migrate from a coarse to a higher-fidelity rendering of the icing hazard within the radar volume context. This will be achieved through continued analysis of many more storms, particularly now that the NEXRAD network has a dual-polarization capability. Collaborations with in situ probing and ground-based complementary sensor networks within view of dual-polarization radars (Williams et al. 2015) should further the connection between the radar returns and the physics of icing in the atmosphere.

Acknowledgments. Discussions with the following individuals contributed much to this work: K. Aydin, L. Carey, F. Cazanave, S. Cohn, M. Gosset, A. Illingworth, J. Hallett, P. Herzegh, A. Khain, V. Melnikov, A. Protat, D. Rosenfeld, A. Ryzhkov, S. Rutledge, T. Takahashi, D. Van de Kamp, M. Weber, and D. Zrnić. Also recognized are the dualpolarization and winter weather subject matter experts at NSSL and NCAR who are partners with MIT Lincoln Laboratory for the FAA's NEXRAD algorithm program led by T. Webster and B. Bumgarner. This work was sponsored by the Federal Aviation Administration under Air Force Contract FA8721-05-C-0002. Opinions, interpretations, conclusions, and recommendations are those of the authors and are not necessarily endorsed by the U.S. government.

\section{REFERENCES}

Andric, J., M. R. Kumjian, D. S. Zrnić, J. M. Straka, and V. M. Melnikov, 2013: Polarimetric signatures above the melting layer in winter storms: An observational and modeling study. J. Appl. Meteor. Climatol., 52, 682-700, doi:10.1175/JAMC-D-12-028.1.

Auer, A. A., and D. L. Veal, 1970: The dimensions of ice crystals in natural clouds. J. Atmos. Sci., 27, 919-926, doi:10.1175/ 1520-0469(1970)027<0919:TDOICI >2.0.CO;2.

Bader, M. J., S. A. Clough, and G. P. Cox, 1987: Aircraft and dual polarization observations of hydrometeors in light stratiform precipitation. Quart. J. Roy. Meteor. Soc., 113, 491-515, doi:10.1002/ qj. 49711347605 .

Bailey, M. P., and J. Hallett, 2009: A comprehensive habit diagram for atmospheric ice crystals: Confirmation from the laboratory, AIRS II, and other field studies. J. Atmos. Sci., 66, 2888 2899, doi:10.1175/2009JAS2883.1.

Bechini, R., L. Baldini, and V. Chandrasekar, 2013: Polarimetric radar observations in the ice region of precipitating clouds at C-band and X-band radar frequencies. J. Appl. Meteor. Climatol., 52, 1147-1169, doi:10.1175/JAMC-D-12-055.1.

Bringi, V. N., and V. Chandrasekar, 2001: Polarimetric Doppler Weather Radar. Cambridge University Press, $636 \mathrm{pp}$.

Byers, H. R., 1965: Elements of Cloud Physics. University of Chicago Press, $191 \mathrm{pp}$.

Caylor, L. J., and V. Chandrasekhar, 1996: Time-varying ice crystal orientation in thunderstorms observed with multi-parameter radar. IEEE Trans. Geosci. Remote Sens., 34, 847-858, doi:10.1109/36.508402.

Chauzy, S., D. Raisonville, D. Hauser, and F. Roux, 1980: Electrical and dynamical description of a frontal storm deduced from the LANDES 79 experiment. Proc. Eighth Int. Conf. on Cloud Physics, Clermont-Ferrand, France, Amer. Meteor. Soc., 477-480.

Cifelli, R., and S. A. Rutledge, 1994: Vertical motion structure in Maritime Continent mesoscale convective systems: Results from a 50-MHz profiler. J. Atmos. Sci., 51, 2631-2652, doi:10.1175/1520-0469(1994)051<2631:VMSIMC>2.0.CO;2.

Cunningham, J., W. D. Zittel, R. R. Lee, and R. L. Lee, 2013: Methods for identifying systematic differential reflectivity (Zdr) biases on the operational WSR-88D network. Proc. Conf. on Radar Meteorology, Breckenridge, CO, Amer. Meteor. Soc., 9B.5. [Available online at https://ams.confex.com/ ams/36Radar/webprogram/Paper228792.html.]

Dissanayake, A. W., M. Chandra, and P. A. Watson, 1983: Prediction of differential reflectivity due to various types of ice particles and ice-water mixtures. Third Int. Conf. on Antennas and Propagation, Norwich, United Kingdom, IEE Publ. 219, 56-59.

Engholm, C. D., E. R. Williams, and R. M. Dole, 1990: Meteorological and electrical conditions associated with positive cloudto-ground lightning. Mon. Wea. Rev., 118, 470-487, doi:10.1175/ 1520-0493(1990)118<0470:MAECAW >2.0.CO;2.

Evaristo, R., T. M. Bals-Elsholz, E. R. Williams, D. J. Smalley, M. F. Donovan, and A. Fenn, 2013: Relationship of graupel shape to differential reflectivity: Theory and observations. Proc. 29th Conf. on Environmental Information Processing Technologies, Austin, TX, Amer. Meteor. Soc., 14. [Available online at https://ams.confex.com/ams/93Annual/webprogram/ Paper214462.html.]

Field, P. R., R. J. Hogan, P. R. A. Brown, A. J. Illingworth, T. W. Choularton, P. H. Kaye, E. Hirst, and R. Greenaway, 2004: Simultaneous radar and aircraft observations of mixed-phase cloud at the 100-m-scale. Quart. J. Roy. Meteor. Soc., 130, 1877-1904, doi:10.1256/qj.03.102.

Foster, T. C., and J. Hallett, 2002: The alignment of ice crystals in changing electric fields. Atmos. Res., 62, 149-169, doi:10.1016/ S0169-8095(02)00008-X.

$\longrightarrow$, and - 2008: Enhanced alignment of plate ice crystals in a non-uniform electric field. Atmos. Res., 90, 41-53, doi:10.1016/ j.atmosres.2008.02.017.

Hall, M. P., W. F. Goddard, and S. M. Cherry, 1984: Identification of hydrometeors and other targets by dual polarization radar. Radio Sci., 19, 132-140, doi:10.1029/RS019i001p00132.

Hallett, J., and B. J. Mason, 1958: The influence of temperature and supersaturation on the habit of ice crystals grown from the vapor. Proc. Roy. Soc. London, 247A, 440-453, doi:10.1098/ rspa.1958.0199.

Herzegh, P. H., and J. W. Conway, 1986: On the morphology of dual-polarization radar measurements: Distinguishing meteorological effects from radar system effects. Preprints, $23 \mathrm{rd}$ Conf. on Radar Meteorology, Vol. 1, Snowmass, CO, Amer. Meteor. Soc., 55-58.

Hogan, R. J., P. R. Field, A. J. Illingworth, R. J. Cotton, and T. W. Choularton, 2002: Properties of embedded convection in warm-frontal mixed-phase cloud from aircraft and polarimetric radar data. Quart. J. Roy. Meteor. Soc., 128, 451-476, doi:10.1256/003590002321042054.

Hudak, D., B. Currie, P. Rodriguez, S. G. Cober, I. Zawadzki, G. A. Isaac, and M. Wolde, 2002: Cloud phase detection in winter stratiform clouds using polarimetric Doppler radar. Second European Conf. on Radar Meteorology, Delft, Netherlands, ERAD, 90-94. 
Jameson, A. R., M. J. Murphy, and E. P. Krider, 1996: Multipleparameter radar observations of isolated Florida thunderstorms during the onset of electrification. J. Appl. Meteor., 35, 343-354, doi:10.1175/1520-0450(1996)035<0343:MPROOI>2.0.CO;2.

Kennedy, P. C., and S. A. Rutledge, 2011: S-band dual polarization radar observations in winter storms. J. Appl. Meteor. Climatol., 50, 844-858, doi:10.1175/2010JAMC2558.1.

Knight, C. A., and N. C. Knight, 1973: Conical graupel. J. Atmos. Sci., 30, 118-124, doi:10.1175/1520-0469(1973)030<0118: $\mathrm{CG}>2.0 . \mathrm{CO} ; 2$.

Korolev, A., 2007: Limitations of the Wegener-BergeronFindeisen mechanism in the evolution of mixed-phase clouds. J. Atmos. Sci., 64, 3372-3375, doi:10.1175/JAS4035.1.

—-, and I. P. Mazin, 2003: Supersaturation of water vapor in clouds. J. Atmos. Sci., 60, 2957-2974, doi:10.1175/ 1520-0469(2003)060<2957:SOWVIC >2.0.CO;2.

— phase, and ice clouds. J. Atmos. Sci., 63, 2865-2880, doi:10.1175/ JAS3784.1.

, and P. R. Field, 2008: The effect of dynamics on mixed-phase clouds: Theoretical considerations. J. Atmos. Sci., 65, 66-86, doi:10.1175/2007JAS2355.1.

— G. A. Isaac, and J. Hallett, 1999: Ice particle habits in Arctic clouds. Geophys. Res. Lett., 26, 1299-1302, doi:10.1029/ 1999GL900232.

,-- , and — 2000: Ice particle habits in stratiform clouds. Quart. J. Roy. Meteor. Soc., 126, 2873-2902, doi:10.1002/ qj.49712656913.

Krehbiel, P., T. Chen, S. McCrary, W. Rison, G. Gray, and M. Brook, 1996: The use of dual channel circular-polarization radar observations for remotely sensing storm electrification. Meteor. Atmos. Phys., 59, 65-82, doi:10.1007/BF01032001.

Magono, C., and C. W. Lee, 1966: Meteorological classification of natural snow crystals. J. Fac. Sci., Hokkaido Univ., Ser. 7, 2, 321-335.

Marshall, T. C., M. P. McCarthy, and W. D. Rust, 1995: Electric field magnitudes and lightning initiation in thunderstorms. J. Geophys. Res., 100, 7097-7103, doi:10.1029/95JD00020.

Mason, B. J., G. W. Bryant, and A. P. van den Heuvel, 1963: The growth habits and surface structures of ice crystals. Philos. Mag., 8, 505-526, doi:10.1080/14786436308211150.

Matrosov, S. Y., R. F. Reinking, and I. V. Djalalova, 2005: Inferring fall attitudes of pristine dendritic crystals from polarimetric radar data. J. Atmos. Sci., 62, 241-250, doi:10.1175/ JAS-3356.1.

Metcalf, J. I., 1993: Radar observations of the effects of changing electric fields of thunderstorms. Bull. Amer. Meteor. Soc., 74, 1080-1083.

_ 1995 : Radar observations of changing orientations of hydrometeors in thunderstorms. J. Appl. Meteor., 34, 757-772, doi:10.1175/1520-0450(1995)034<0757:ROOCOO >2.0.CO;2.

_ 1997: Temporal and spatial variations of hydrometeor orientations in thunderstorms. J. Appl. Meteor., 36, 315-321, doi:10.1175/1520-0450(1997)036<0315:TASVOH $>2.0 . \mathrm{CO} ; 2$.

Moisseev, D., E. Saltikoff, and M. Leskinen, 2009: Dual-polarization weather radar observations of snow growth processes. Preprints, 34th Conf. on Radar Meteorology, Williamsburg, VA, Amer. Meteor. Soc., 13B.2. [Available online at https://ams. confex.com/ams/pdfpapers/156123.pdf.]

, S. Lautaportti, L. Bliven, V. Chandraskekar, and M. Kulmala, 2012: Aggregation growth of snowflakes observed by radar and ground-based particle video imager. 16th Int. Conf. on Clouds and Precipitation, Leipzig, Germany, International Commission on Clouds and Precipitation-International Association of Meteorology and Atmospheric Sciences, P4.30. [Available online at http://iccp2012.tropos.de/.]

Noel, V., and K. Sassen, 2005: Study of planar ice crystal orientation in ice clouds from scanning polarization lidar observations. J. Appl. Meteor., 44, 653-664, doi:10.1175/JAM2223.1.

Plummer, D. A., S. Goke, R. M. Rauber, and L. Di Girokamo, 2010: Discrimination of mixed-phase versus ice-phase clouds using dual-polarization radar with application to detection of aircraft icing regions. J. Appl. Meteor. Climatol., 49, 920-936, doi:10.1175/2009JAMC2267.1.

Russell, B., and Coauthors, 2010: Radar/rain-gauge comparisons on squall lines in Niamey, Niger for the AMMA. Quart. J. Roy. Meteor. Soc., 136, 289-303, doi:10.1002/qj.548.

Sauvageot, H., K. Kouadio, and C.-A. Etty, 1986: The influence of temperature and supersaturation on the polarization of radar signals. Preprints, Conf. on Radar Meteorology, Vol. 1, Snowmass, CO, Amer. Meteor. Soc., 173-176.

Schaefer, V. J., and J. A. Day, 1981: A Field Guide to the Atmosphere. Houghton Mifflin, $359 \mathrm{pp}$.

Seliga, T. A., and V. N. Bringi, 1976: Potential use of radar differential reflectivity measurements at orthogonal polarizations for measuring precipitation. J. Appl. Meteor., 15, 69-76, doi:10.1175/1520-0450(1976)015<0069:PUORDR > 2.0.CO;2.

Steinert, J., and M. Chandra, 2009: Classification of ice crystals at C-band. Adv. Radio Sci., 7, 273-277, doi:10.5194/ars-7-273-2009.

Takahashi, T., 1978: Riming electrification as a charge generation mechanism in thunderstorms. J. Atmos. Sci., 35, 1536-1548, doi:10.1175/1520-0469(1978)035<1536:REAACG >2.0.CO;2. , 2010: The videosonde system and its use in the study of East Asian monsoon rain. Bull. Amer. Meteor. Soc., 91, 1232-1246, doi:10.1175/2010BAMS2777.1.

Teschl, F., W. L. Randeu, M. Schönhuber, and R. Teschl, 2008: Simulation of polarimetric radar variables in rain at $\mathrm{S}-, \mathrm{C}-$, and X-band wavelengths. Adv. Geosci., 16, 27-32, doi:10.5194/ adgeo-16-27-2008.

Thompson, E. J., S. A. Rutledge, B. Dolan, V. Chandrasekhar, and B. L. Cheong, 2014: A dual-polarization radar hydrometeor classification algorithm for winter precipitation. J. Atmos. Oceanic Technol., 31, 1457-1481, doi:10.1175/JTECH-D-13-00119.1.

Vivekanandan, J., V. N. Bringi, M. Hagen, and P. Meischner, 1994: Polarimetric radar studies of atmospheric ice particles. IEEE Trans. Geosci. Remote Sens., 32, 1-9, doi:10.1109/36.285183.

Weinheimer, A. J., and A. A. Few, 1987: The electric field alignment of ice particles in thunderstorms. J. Geophys. Res., 92, 14 833-14 844, doi:10.1029/JD092iD12p14833.

Williams, E. R., 1989: The tripole structure of thunderstorms. J. Geophys. Res., 94, 13151-13167, doi:10.1029/JD094iD11p13151. _, and W. Ecklund, 1992: $50 \mathrm{MHz}$ profiler observations of trailing stratiform precipitation: Constraints on microphysics and in situ charge separation. Preprints, 11th Conf. on Clouds and Precipitation, Montreal, QC, Canada, International Commission on Clouds and PrecipitationInternational Association of Meteorology and Atmospheric Sciences, 754-757.

_ - and Coauthors, 2011: Dual polarization radar winter storm studies supporting development of NEXRAD-based aviation hazards products. Proc. 35th Conf. on Radar Meteorology, Pittsburgh, PA, Amer. Meteor. Soc., 202. [Available online at https:// ams.confex.com/ams/35Radar/webprogram/Paper191770.html.] D. Smalley, M. Donovan, R. Hallowell, M. Wolde, M. Bastian, A. Korolev, and R. Evaristo, 2013a: Validation of NEXRAD radar differential reflectivity measurements in 
snowstorms with airborne microphysical measurements: Evidence for hexagonal flat plate crystals. Proc. 36th Conf. on Radar Meteorology, Breckenridge, CO, Amer. Meteor. Soc., 15A.6. [Available online at https://ams.confex.com/ams/ 36Radar/webprogram/Paper228791.html.]

— differential reflectivity with metal spheres. Proc. 36th Conf. on Radar Meteorology, Breckenridge, CO, Amer. Meteor. Soc., 15.316. [Available online at https://ams.confex.com/ams/ 36Radar/webprogram/Paper228796.html.]

_, M. F. Donovan, D. J. Smalley, R. G. Hallowell, E. Griffin, K. T. Hood, and B. J. Bennett, 2015: The 2013 Buffalo Area Icing and Radar Study (BAIRS). MIT Lincoln Lab. Rep. ATC-419, 132 pp.

Wolde, M., and G. Vali, 2001a: Polarimetric signatures from ice crystals observed at $95 \mathrm{GHz}$ in winter clouds. Part I:
Dependence of crystal form. J. Atmos. Sci., 58, 828-841, doi:10.1175/1520-0469(2001)058<0828:PSFICO > 2.0.CO;2. , and —_, 2001b: Polarimetric signatures from ice crystals observed at $95 \mathrm{GHz}$ in winter clouds. Part II: Frequencies of occurrence. J. Atmos. Sci., 58, 842-849, doi:10.1175/ 1520-0469(2001)058<0842:PSFICO > 2.0.CO;2.

Zrnić, D. S., N. Balakrishan, C. L. Ziegler, V. N. Bringi, K. Aydin, and T. Matejka, 1993: Polarimetric signatures in the stratiform region of a mesoscale convective system. J. Appl. Meteor., 32, 678-693, doi:10.1175/1520-0450(1993)032<0678: PSITSR $>2.0 . \mathrm{CO} ; 2$.

, R. Doviak, G. Zhang, and A. Ryzhkov, 2010: Bias in differential reflectivity due to cross coupling through the radiation patterns of polarimetric weather radars. J. Atmos. Oceanic Technol., 27, 1624-1637, doi:10.1175/ 2010JTECHA1350.1. 